\title{
Favourable and Unfavourable EMF Frequency Patterns in Cancer: Perspectives for Improved Therapy and Prevention
}

\author{
Dirk K. F. Meijer1" ${ }^{*}$, Hans J. H. Geesink ${ }^{2}$ \\ ${ }^{1}$ University of Groningen, Groningen, The Netherlands \\ ${ }^{2}$ Biophysics Group, Loon op Zand, The Netherlands \\ Email: *meij6076@pla net.nl
}

How to cite this paper: Meijer, D.K.F. and Geesink, H.J.H. (2018) Favourable and Unfavourable EMF Frequency Patterns in Cancer: Perspectives for Improved Therapy and Prevention. Journal of Cancer Therapy, 9, 188-230.

https://doi.org/10.4236/jct.2018.93019

Received: January 15, 2018

Accepted: March 9, 2018

Published: March 12, 2018

Copyright $\odot 2018$ by authors and Scientific Research Publishing Inc. This work is licensed under the Creative Commons Attribution International License (CC BY 4.0).

http://creativecommons.org/licenses/by/4.0/

\begin{abstract}
Carcinogenesis fits in a frequency pattern of electromagnetic field (EMF) waves, in which a gradual loss of cellular organization occurs. Such generation of cancer features can be inhibited by adequate exposure to coherent electromagnetic frequencies. However, cancer can also be initiated and promoted at other distinct frequencies of electromagnetic waves. Both observations were revealed by analyzing 100 different EMF frequency data reported in a meta-analyses of 123 different, earlier published, biomedical studies. The studied EM frequencies showed a fractal pattern of 12 beneficial (anti-cancer) frequencies, and 12 detrimental (cancer promoting) frequencies, that form the central pattern of a much wider self-similar EMF spectrum of cancer inhibiting or promoting activities. Inhibiting of the cancer process, and even curing of the disease, can thus be considered through exposure to the coherent type of EM fields. Stabilization of the disease can be understood by constructive resonance of macromolecules in the cancer cell with the externally appied coherent EMF field frequencies, called solitons/polarons. The latter, for instance, have been shown earlier to induce repair in DNA/RNA conformation and/or epigenetic changes. The field of EMF treatment of cancer disorders is rapidly expanding and our studies may invite further experimental and clinical studies in which systematically various potential EMF treatment protocols could be applied, with combined and modulated frequencies, to obtain even more efficient EMF anti-cancer therapies.
\end{abstract}

\section{Keywords}

Cancer Therapy, Coherent EMF Frequencies, Non-Coherent EMF

Frequencies, Electromagnetic Fields, Solitons, Non-Ionizing EM Radiation, Fröhlich, Davydov 


\section{Introduction}

The present study was performed to provide a systematic overview of electromagnetic (EM) frequencies that influence cancer processes, through a meta-analysis of earlier scientific reports on the effects of EM fields on life systems in vitro and in vivo, in the framework of cancer experimentation. A second aim was to apply these data to further unravel the biomolecular and biophysical mechanisms that may play a role in this widespread group of diseases, with special reference to the role of a discovered semi-harmonic oscillatory wave pattern system of cellular macromolecules that determine a proper functional structure of the cell.

The entire list of relevant data out of the investigated literature can be found in Appendix, beneficial frequencies and detrimental frequencies, while further details of the experiments analyzed can be found in Appendix 1. Studies were included in the present meta-analyses on the basis of, mostly, peer reviewed articles, using well defined radiation technology and exposure characteristics, containing statistically significant and reproducible data as well as clearly describtion of the particular positive or negative effects. A, single glimpse, overview of the present results is depicted in Figure 1.

Fröhlich pioneered in this approach by proposing that the functionality in living systems results from ordered vibratory states influencing the apparently chaotic motions and arrangements of biological molecules. An important feature is that ordered or coherent states can be manifest over large distances, thus offering a mechanism by which cells can intercellular and intracellular communicate, in addition to the known short range chemical forces. This long-range biological coherence provides the growth control as it exists in healthy tissue but is absent in cancer [1]. A number of investigators have expanded Fröhlich's

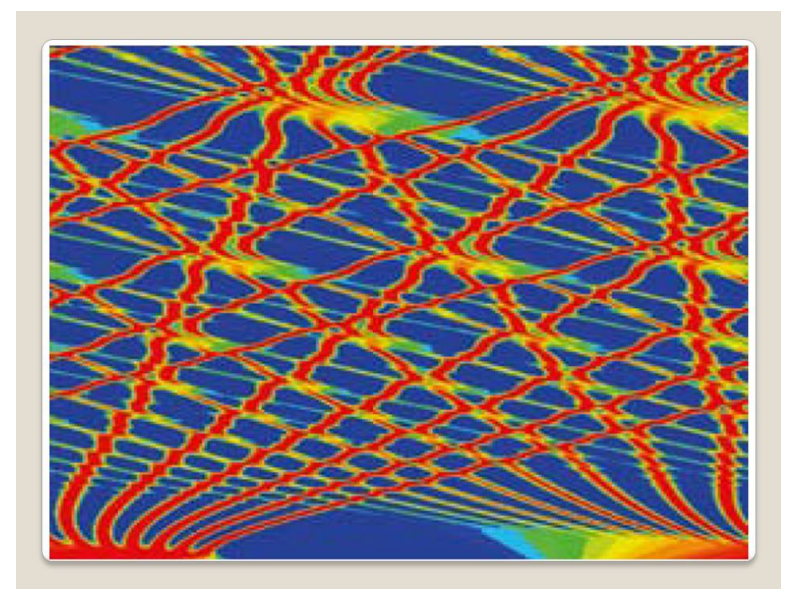

Figure 1. Solitons propagate in either direction, exchange positions and eventually return the system to states that resemble their initial configuration. The motion of the solitons can be seen here by following the lines of colours, which denote displacements (From Porter, 2009 and image from Zabusky, Sun and Peng 2006). 
concept, and aimed at testing the predicted conditions experimentally [2] [3]. Adey proposed a model by which weak EM signals could be transmitted through cell membranes and how solitary waves may carry weak signals inside cells. Preto provided a general classical Hamiltonian description of a nonlinear open system of biomolecular structures exhibiting multiple degrees of freedom, that can be excited by an external energy source. It was shown that a coherent behavior, similar to Fröhlich's effect, is to be expected for a given range of discrete parameter values [4]. Direct experimental support for the presence of Fröhlich condensation to coherent vibratory cell domains, and the related action in the arrangement of proteins, was found by spectroscopic detecting of Bose-Einstein condensate-like structures in biological matter at room temperature [5].

Coherence is defined as the physical congruence of wave properties within wave packets. It is a known property of stationary waves (i.e. temporally and spatially constant) that enables a type of wave interference, defined as constructive. Constructive wave interference leads to the generation of specific resonance patterns, promoting coherent cellular wave domains, and dynamic cell systems are partially operating via this principle. Coherence or non-randomness of quantum resonances has also been discussed by Einstein and Infield in 1961 for the so-called "prequantum modes". It was Schrödinger who recognized that coherent interaction of waves is coupled to entanglement as "the characteristic aspect of quantum mechanics" and suggested that "eigenstates", also called "preferred states" are able to survive interaction with the environment. Coherent resonances can be present in electrons, photons, phonons and quasi-paricles such as solitons. The preferred location for resonance transfer in living cells are the surrounding domains of ion water clathrates, nucleic acids and ion-protein complexes. Water molecule arrangements are known to be coherently nano-structured and the resulting coherent domains affect bio-molecular processes, including protein conformation and stability, substrate binding to enzymes, as well as electron and proton transfer [6] [7] [8]. Semikhina documented that alternating magnetic fields in the range $25 \mathrm{nT}-879 \mu \mathrm{T}$ are able to disrupt the arrangement of water molecules, particularly under high concentrations of hydrogen bonds and protons. The effects were absent above $40^{\circ} \mathrm{C}-50^{\circ} \mathrm{C}$, as water structure changes. The maximum effect was detected at $156.2-\mathrm{Hz}$ and $15.45 \mu \mathrm{T}$ for $7^{\circ} \mathrm{C}$ pure water (of note: that value is very close to the some of the calculated non-coherent frequencies revealed in our life algorithm) [9] [10].

According to Henry two main regimes of aqueous solutions exist containing solutes species either as small ions or large colloids: 1) an incoherent regime when the concentration is not high enough to favor phase locking between matter, radiation and vacuum and 2) a coherent regime of phase locking between coherence domains, above a certain threshold of concentration, depending upon the nature of the added salts. The characteristic feature of his model is that the coupling between matter fields (water, ions, colloids) and the electromagnetic field, originating in the vacuum, is not zero as in classical theories [11]. 
If cells, bio-molecules, and cell networks are organized such that coherency of waves and wave patterns is at stake, a physical relation should exist between this property and the stability of the components. A coherent pattern within a life-algorithm of electromagnetic field-frequencies for living cells was earlier inferred by us in a meta-analysis of bio-medical literature [12] [13]. The observed coherent resonances in life systems were subsequently matched to a Pythagorean scale of tuning and octave hierarchy. Interestingly a similar set of frequencies was earlier detected in non-animate systems: the particular EM frequencies turned out to be related to eigenvalues of a square oscillating plate (Ritz, 1909). We inferred that living organisms function against a background of such coherent resonances, at the level of molecules, their functional aggregates, overall cell architecture and and possibly even at the neuronal level of conscious perception [14]. Coherency may be related to solitons that play a role as self-reinforcing solitary waves and are seen as electromagnetically longitudinal, helical and radial waves that travel along proteins, microtubules and DNA (ref). They thereby may induce an endogenous coherent electromagnetic field and stabilize local resonant oscillations and/or induce electronic excitations of neighbouring molecules and macromolecules. The corresponding soliton frequency-zones are considered to be responsible for the coherent wave patterns in cells. It was hypothesized by us that such wave energies are collected in, so called, underlying toroidal space-time operators and that the particular multi connectedness can be optimally expressed by adopting a toroidal geometry [14]. From these studies a bio-soliton model has been derived that describes a spectrum of electromagnetic eigen-frequencies of which coherent and non-coherent frequencies are ordered in an alternate fashion. This knowledge can be applied to understand physical principles of biological effects in living cells, as caused by electromagnetic fields [13]. The model is complementary to Henry's model of characteristic frequencies involving water molecules by relating the molecular weight $\mathrm{M}$ of any solvent or solute species to EM frequencies, using the mass-energy equivalence coupled to the Planck-Einstein relationship [11].

We envision that a resulting soliton based morphogenetic field provides a dedicated control of functional shape of life structures, through bringing in positional information and cues, in order to regulate organism-wide system properties like cellular architecture, including control of reproduction and repair. It is proposed that the most optimal architectural state of a living cell is such a coherent state, and that decline of quality of cell properties can occur when a transition takes place from coherent states to states of less coherence, that can lead to moderate no-coherence or even to a state a full non-coherence.

The highest coherent state can be defined as an integral fine tuned assembly of such coherent soliton frequencies. Our soliton model may predict which discrete eigen-frequencies of non-thermal electromagnetic waves are life-sustaining and which are not. The particular effects were found to be exerted by a range of electromagnetic wave frequencies of one-tenth of a Hertz till Peta Hertz (at $\mathrm{Hz}$, $\mathrm{KHz}, \mathrm{Mhz}, \mathrm{GHz}, \mathrm{THz}$ en $\mathrm{PHz}$ ), and showed a distribution pattern of twelve 
bands within one octave, that can be positioned in a normalized acoustic-like frequency scale. This means that, over the whole octave-extended frequency range, in total up to 400 beneficial and 400 detrimental frequency bands may play a crucial organizing role in living cells.

It is further known that the architectural geometry of living cells, like genetic and epigenetic expression, can be disturbed by decoherent wave modalities. Interestingly, decoherent wave information can also be restored in a reversed process, that was called decoherence-coherence state cycling [15].

\section{Hypothesis: Cancer Is Due to a State of Loss of Internal Cellular Organization and em Coherence}

Various physical models about the origin of carcinogenesis on the basis of biophysical mechanisms were proposed earlier. In the following, we will shortly treat a selection of these theories:

\section{Plankar et al.}

Cancer was postulated to be essentially a non-genetic disease, characterised by a global and unspecific impairment of energy and information flow through the system, as manifested in genomic, transcriptomic and proteomic dysregulation. It is primarily characterized by an unspecific progressive self-disorganisation, and impairment of the proper coherent dynamics at some specific levels [16] [19].

\section{Sonnenschein and Soto}

Carcinogenesis was seen as a problem of tissue organization: carcinogenic agents destroy the normal tissue architecture disrupting cell-to-cell signaling and thereby compromise genomic integrity. Single or multiple carcinogenic exposure acts in a given morphogenic field, disturbing the reciprocal biophysical communication between the parenchyma and the mesenchyme/stroma [17] [18].

\section{Pokorný et al.}

Impaired coherence was linked to the bioenergetic aspect of cancer considering Fröhlich's theory. Cancer has a lower degree of overall coherency. Healthy cells and the organization of living matter depends on a morphogenetic pattern formation, and a field that determines the morphological structure of living organisms [16].

\section{Levin and Chernet}

Cancer was interpreted as corrupted geometry: a misregulation of the field of information that orchestrates individual cell activity with regard to normal anatomy. The view that cancer is a developmental disorder, predicts that molecular mechanisms, known to be important mediators of the supposed morphogenetic field, are deranged and thereby would be involved in tumorgenesis. Failure of morphostasis can occur in cancer, because the entite morphogenetic field is missing, altered, or not successfully perceived. This can occur due to selective genetic or physiological state changes [20] [21] [22].

\section{Knox and Funk}

A context dependent model was focused on interactions between the cell and its surrounding environment as the initiator and/or driver of malignancy. Ge- 
nome wide epigenetic changes precede cancer and confer risk for cancer. This strongly suggest that multiple systems are affected by changes in gene expression, even before tumors become manifest. Biophysical signalling was considered as having a central role in cancer, through influences on cell proliferation, cell cycle progression, apoptosis, orientation of cell migration, as well as cell differentiation [23].

\section{Maziarz et al.}

External electromagnetic fields (EMF's) can influence adult stem cells resulting in either positive or negative effects. Endogenous EMFs are present in developing and regenerating tissues and organs, either in the extracellular space or in the cell cytoplasm. It has been hypothesized that some specific ranges of EMF parameters promote regeneration but others result in cancer formation, degeneration, and pathological alterations. The observed osteogenic and chondrogenic differentiation of mesenchymal stem cells show that EMF stimulation affects not only proliferation, the cell cycle, or differentiation of stem cells, but also the many correlated processes. Stem cells under the influence of "improper stimuli" may contribute to carcinogenesis and pathological alterations, resulting in many chronic disorders [24].

\section{Tuszynski et al.}

A non-uniform field will lead to the development of dielectrophoretic forces, acting on polarizable macromolecules such as microtubules, and organelles. This can affect all charged structures present in the cell, such as ions, proteins or DNA. A model has been proposed, related to ionic solitary condensation waves around microtubules. In addition dielectrophoretic effects in dividing cells may act on the dipole moments of microtubules at intermediate frequencies. The whole cytoskeleton, and especially microtubulins, participate in numerous collective interactions with electromagnetic forces, due to the complex charge distribution in and around the particular protein filaments that are surrounded by poly-ionic solutions. Solitary ionic waves have been described as solutions of a nonlinear partial differential equation [25].

\section{Popp}

Biophoton emissions from healthy humans display rhythmic patterns and show coherence. Biophotons emitted from cancer cells lack coherence and fail to follow natural rhythmic patterns. Popp hypothesized that cancer results from a disruption of cell's photorepair system and discovered that benzo[a]pyrene, a potent carcinogen, absorbs ultraviolet light at 380 nanometers and emits it at another frequency [26] [114].

\section{Le Chapellier and Matta}

An explanation of the action mechanism of solitons upon pancreatic tumor is proposed. A non-linear system which emits dissipative solitons is sensitive to the presence of an external structure of frequencies. According to biophysics, the exposure of the cellular medium to solitons sensible for radiofrequencies tends to produce a coherent structuring [27]. 


\section{Gao and $\mathrm{Li}$}

Comparisons between primary cancers and metastases suggest a hypothesis of biological resonance (bioresonance). Primary cancer and matched metastasis have a common progenitor, while both ancestors are under similar microenvironments and receive similar or same signals. When their interactions reach a status similar to primary cancer, metastasis will occur [28].

\section{Influences of Non-Ionizing Electromagnetic Fields on Biological Parameters}

Research about electromagnetic pulses on living cells has been systematically undertaken the past eighty years. About 25.000 biological and physical reports are available, of which a large part is dealing with non-thermal biological effects on living cells. Influences of electromagnetic waves causing thermal effects on biological systems are known and relatively well understood. Importantly, to date considerable knowledge about non-thermal effects of electromagnetic waves has become available. At least six physical principles about the behaviour of non-ionizing radiation concerning biological effects of living cells have been proposed: 1) ion-cyclotron resonances, 2) parametric resonance, 3) interactions between electromagnetic fields and electrons, 4) resonant frequencies and polarisation, 5) resonant recognition, 6) radical concentrations, and 6) stability of waves and quantum coherence.

\section{Research of Belyaev et al.}

Non-thermal electromagnetic fields (EMF) are able to cause both beneficial and detrimental responses of living cells (see 29-36). These have been mainly observed in the wide frequency ranges of extremely low frequencies $(1-300 \mathrm{~Hz})$ and microwave frequencies $(300 \mathrm{MHz}$ to $300 \mathrm{GHz}$ ). There is strong evidence from many studies that biological effects of EMF are related to various physiological and physical parameters. Electromagnetic waves can affect overall cell viability, and may influence neural and osteogenic differentiation, gene expressions, epigenetic mechanisms, as well as chromatin modifications. Stem cells are more sensitive to EMF exposure than differentiated human primary cells, lymphocytes, and fibroblasts, whereas fibroblasts are the least sensitive. Non thermal EMF's biological effects depend on various physical wave or field parameters: intensity, overall duration and intermittent or permanent exposure, frequency, polarization, modulations such as pulses, amplitudes, phases, and complex moduli, in addition to intermittence, near field/far field and static magnetic field. Of note, even small changes in carrier frequency of about $2-4 \mathrm{MHz}$ can result in disappearance of non-thermal microwave (MW) effects, because of the selectivity of resonance like responses. Also, relatively small changes in carrier frequency, in the order of $10 \mathrm{MHz}$, has reproducibly resulted in cell-type-dependent generation of effects on non-thermal EMF exposure with respect to DNA repair foci in human cells. Coherence modulations of MW waves often play a crucial role [29]-[42]. 


\section{Potential treatments of various cancer types}

A positive consequence of all this, is that treatment of melanoma, by applying external non-ionizing electromagnetic fields, is possible. Nanosecond pulsed electric field (NsPEFs) treatment is able to induce locally apoptosis-like effects of melanoma and affect vascular networks, both promoting tumor demise and restoration of normal vascular homeostasis. Electromagnetic stimulation technology is already been used to treat various cancer types including skin, breast, prostate, hepatocellular, lung, ovarian, pancreatic, bladder, thyroid, and colon cancer in vitro and in vivo [43] [44]. A combined treatment of PEF (pulsed electromagnetic waves) and Co-gamma radiation shows a significant effect on delaying the growth of glioma and subcutaneously implanted tumors [45].

Stem cell biology have opened a new window in the expanding area of regenerative medicine based on tissue engineering and cell therapy derived from a variety of stem cells. Effects of EMFs on human adult stem cell biology have been studied, such as proliferation, the cell cycle, differentiation and properly adjusted values of EMF frequencies, as well as times of stimulation [24]. Neurogenesis and osteogenesis processes rely on the activation of specific and complex transcriptional programs, while epigenetic mechanisms play a critical regulatory role. This can be realized by translating a wide array of endogenous and exogenous signals into persistent changes in gene expression in both neural stem cells and mesenchymal stem cells. EMF stimulation has been recognized as an effective tool in promoting both neurogenesis and osteogenesis and the studies performed, so far, point to chromatin remodeling and pro-neuronal gene expression [46].

\section{Coherence versus Loss of Coherence in Relation to Cancer}

The organisation of components of a life system can be logical and well-organized in a biological sense or show chaotic aspects, which is often related to the terms coherent or non-coherent respectively. Of note, the organised pattern of the cell components can be stable, or instable as well as in equilibrium or far from equilibrium. In physics, waves are called coherent when the phase differences between the waves is small, whereas, if waves are defined as incoherent, these phases have a high degree of variability [14]. We proposed that life bio-molecules and viable cells are exposed to and are functioning within about $400 \mathrm{~Hz}$ narrow EM field frequency bands over a broad spectrum of frequencies. The individual values that form quite narrow frequency bands, are localized around highly coherent frequencies. They, apparently, fit with a discrete pattern of coherent waves and, in our view, may be co-responsible for the architectures of living cells. The particular, highly coherent, frequencies of living cells/molecules are thus positioned in "coherent zones" and exist within in a small bandwidth of $0.85 \%$ of the local coherent algorithmic frequency. In contrast, non-coherent zones are positioned just in between the coherent zones and are responsible for a destabilization of cellular organization, also within a small bandwidth of $0.85 \%$ of the local decoherent algorithmic frequency. Cell-sustaining properties are posi- 
tioned at the green points, see Figure 2, while cell-destabilizing non-coherent frequencies are positioned between the cell-sustaining frequency bands at the red squares. We proposed: 12 coherent reference semi-harmonic frequencies: 256, 269.8, 288, 303.1, 324, 341.2, 364.7, 384, 404.5, 432, 455.1, $486 \mathrm{~Hz}$, and 12 decoherent frequencies positioned logarithmical just in between these coherent frequencies: $249.4,262.8,278.8,295.5,313.4,332.5,352.8,374.3,394.1,418.0$, 443.2, 470.3 Hz.(see Figure 2). All other frequencies, situated below or above the range of Figure 2, can be simply derived by octave hierarchy.

Fröhlich did already present the first explicit hypothesis on the role of coherence in cancer and laid the basis for understanding the related physical processes in biological systems. The central item is that cancer transformation pathways include a link with altered coherent electric (electromagnetic) vibrations. He proposed that a global (localy extended) coherent excitation emerges from electrically polar structures of sufficient size and polarisation density spans across the tissues. These may also exert a long-range communication between cells, thereby electro-mechanically stabilising the whole tissue. A cancer cell may escape from such interactions with the surrounding healthy cells and individual cells may then exhibit independent activity, that is if the frequency spectrum is perturbed and/or shifted. Such frequency changes may be combined with disturbances of the spatial pattern of the field by which the transformed cell becomes dissociated from local interactions and tends to perform local invasion and formation of metastases. When a critical number of cells cease to be in resonance with the global local excitation, they will no longer be under tissue control and will express their tendency to divide again, a state which Fröhlich identified with cancer [50] [51].

Devyatkov has considered the same principle of interactions of biomolecules and living cells. He found that biological effects of cells, exposed to electromagnetic

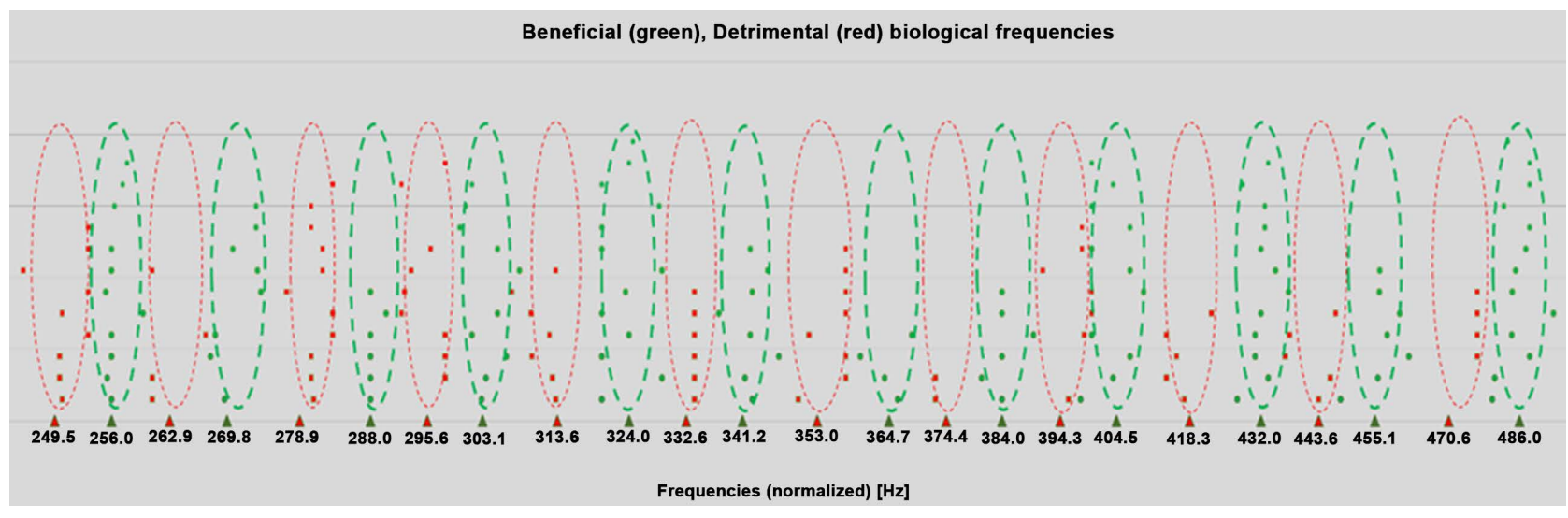

Figure 2. EM frequencies that were experimentally applied to living cells systems reported in 219 separate biomedical studies, plotted on a semi-harmonic logarithmic reference GM-scale, are found to be patterned in 12 apparent bands of in total 143 life-sustaining coherent frequencies (green points) and 77 cell-destabilizing non-coherent frequencies (red squares). The latter are clearly positioned between the life-sustaining frequency bands. Each point indicated in the graph represents an individual experiment. For clarity, points are evenly distributed along the $\mathrm{Y}$-axis, according to the number of experiments within each apparent frequency band. 
waves, are dependent on: wavelength, wave modulations, dose, exposure time, magnetic field and coherence. He discovered that cells may be affected by long series of combined frequencies, to be considered as second and third harmonics of these frequencies, providing oscillations of a, so called, collective mode [53] [54] [55].

Also Popp has hypothesized that cancer results from a disruption of cells' photorepair system and that biophoton emissions from cancer cells lack coherence and fail to follow natural rhythmic patterns [26].

Physical mechanisms of non thermal EMF effects have been explained in the framework of nonequilibrium and nonlinear systems and investigated by many researchers: Fröhlich [46]-[52], Davydov [56] [57], Frey [58], Adey [3] [59] [60] [61] [62], Liboff [63], Szmigielski [64], Blank [65], Salford [66], Binhi [67], Blackman [68] [69], Carpenter [70], Belyaev [32] [70]-[78], Brizhik [79] [80], Cifra [81] [82], Pokorný [83] [84] [85], Srobar [86] [87] [88], Cosic [89], Havas [90], and Barnes [91].

Our proposed soliton model describes that a high level of coherence of waves for healthy living cells is realized when the absolute distance between a distinct endogeneous or exogeneous frequency in relation to a coherent frequency is positioned in the soliton algorithm in the range of $0.0 \%-0.85 \%$ of the particular value. A moderate level of coherence is defined when the absolute distance between a typical frequency and a calculated soliton coherent frequency is between $0.85 \%-1.25 \%$. A clear decay of organizational frequencies of living cells can occur when the absolute distance between the observed frequency and the calculated coherent frequency is between $1.25 \%-2.50 \%$, while a maximum decay can take place around $2.50 \%-3.0 \%$ [13]. About 400 typical coherent solitonic frequencies were detected in literature to sustain healthy living cells. This implies either an endogeneous and or an exogeneous filed, yet both can be modeled as vortex like movements if positioned on a toroidal rotatory structure. About 400 typical decoherent solitonic frequencies sustain the organizational decay of healthy living cells and can be positioned at the vortices of a toroid [13]. The torus, like a twistor, is seen as the basic space-time structure, acting as an operator for the processing of quantum wave information.

\section{Prevention of Carcinogenesis and Collective Evidence for Our EM-Mediation Hypothesis}

Carcinogenesis is, according to $\mathrm{H}$. Fröhlich, Davydov and the earlier discussed models, conceived as having a relation with the above mentioned "organized field", and thus with electrodynamics in and around living bio-molecules/cell(s). The "organized field" is supposed to interact with EM vibrations such as solitons that represent nonlinear interactions of vibrational excitations in and around biomolecules at typical frequencies [13]. Solitons are self-reinforcing solitary waves and have an electromagnetic character exhibiting a longitudinal, helical and radial aspects. Organisms undergo changes in the form of successive trans- 
formations of organization states of cells during morphogenesis and tissue repair [92].

A first extensive meta-analysis of in total 320 published biological and medical studies has earlier been performed by us, (Geesink and Meijer, 2015, Meijer and Geesink, 2016), in which living material (tissues, cells, and whole animals) was exposed to external electromagnetic fields employing a wide spectrum of frequencies from $\mathrm{Hz}, \mathrm{Khz}, \mathrm{Mhz}, \mathrm{GHz}, \mathrm{THz}$ and $\mathrm{PHz}$ mainly in the area of non thermal biological effects. In these studies the various effects of the electromagnetic fields were reported as to their potential to inhibit and retard cancer, as opposed to initiation and promotion of cancer. After collecting and scrutinizing the distribution pattern of these data, the following parameters were established: 1) frequency values: ( $\mathrm{Hz}, \mathrm{kHz}, \mathrm{Mhz}$ and $\mathrm{GHz}, \mathrm{THz}$ and $\mathrm{PHz}), 2)$ particular frequency modulations, 3) combinations of frequencies, and 4) chosen exposure levels. The summarized frequency data were subsequently ordened to identify the most nearby soliton frequencies, according to the proposed algorithm and subsequently to calculate the relative difference between the frequencies applied in the biological studies and the most nearby calculated soliton frequencies, and than expressed in \% of the algorithmic values. The apparent frequency zones, which are located between the designated regions of stabilization and destabilization, are regarded to represent transformational zones of geometric wave patterns. The bandwidth of such frequency transformation zones were estimated to be located at about $0.50 \%$ of each local coherent frequency band

To further verify this hypothesis, 123 published papers from 1965 untill now, have been re-analyzed that describe the inhibition/retardation or initiation/promotion of cancer, both in relation to the applied exogeneous electromagnetic waves. In addition some examples of supposed endogeneous EM waves were analyzed (see for the collected data of this meta-analysis the Appendix 1). A total of 95 frequency data $(\mathrm{Hz}-\mathrm{THz})$ of in vitro and in vivo biological experiments could be selected that show inhibition/retardation cancer or initiation/promotion/representing cancer. All frequency data have been normalized according to octave hierarchy and can be positioned at a normalized semi-harmonic frequency scale $(\mathrm{Hz})$, called the GM-scale, see Figure 3. It can be concluded that the electromagnetic frequencies of all experiments showing inhibition/retardation of cancer are precisely positioned in frequency bands already found for cell-sustaining frequencies (green points, Figure 2 and Figure 3). All experiments showing initiation/promotion/representing cancer are precisely positioned in frequency bands already found for cell-destabilizing frequencies (red squares, Figure 2 and Figure 3).

It can be further confirmed that carcinogenesis and cancer growth is likely to be associated with a non-coherent character of electromagnetic waves and related quantum states. On the other hand, inhibition and curing of cancer turn out to be coupled to a coherent behavior of electromagnetic waves and quantum states, according to the proposed algorithm of frequencies. Importantly, it 


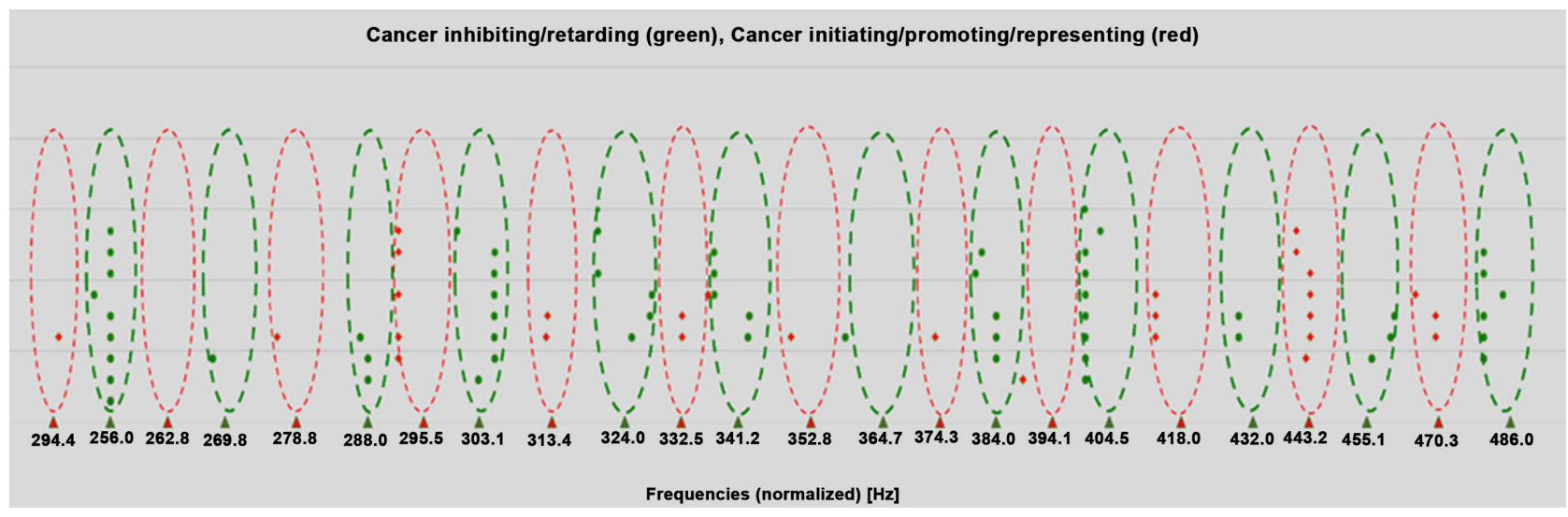

Figure 3. EM frequencies (in total 95) that were experimentally applied to living cells systems, and plotted logarithmically on an acoustic algorithmic GM-scale, are found to be patterned in 12 apparent bands of cell-sustaining coherent frequencies that are able to inhibit/retard cancer (green points) and non-coherent frequencies able to initiate/promote/represent cancer (red squares), the latter are positioned between the cell-sustaining frequency bands. Each point indicated in the graph represents an individual experiment as registered in 123 biomedical studies on cancer. For clarity, points are evenly distributed along the Y-axis, according to the number of experiments within each apparent frequency band.

follows that curing or inhibition of cancer can be achieved by exposure to electromagnetic frequency conditions that are beneficial for cells.

Subsequently, the different frequency effects of electromagnetic waves on living cells were also analysed with regard to cell differentiation, DNA compostion, chromosomal aspects, genetic expressions, genome-wide methylation, foci in differentiated cells, stem cells, neurons, plasma membranes, germ cells, signalling path ways, cognitive effects, learning, spatial memory, and cell death among others (Appendix 2).

\section{Direct Measurement of EM Wave Frequencies in Tumor Tissues}

Endogeous measurements at $\mathrm{EM} \mathrm{MHz}$ frequencies in cancer cells, fully supported the proposed hypothesis. Damping of external electromagnetic field caused by cancer tissue has been for example measured at a frequency of 465 $\mathrm{MHz}$ including the first harmonic. The absorption resonant frequencies of some tumors around $465 \mathrm{MHz}$ was estimated as a distinct shift of spectral lines of normal cells (Vedruccio, 2004, 2011), see Appendix 2.

The principle of detection lies in the resonance between the coupled active nonlinear oscillator (the probe) and the passive oscillator (the tissue) in the radiofrequency range of the electromagnetic spectrum. The external electromagnetic field is damped by cancer tissue for example at $465 \mathrm{MHz}$ and its first harmonic and only on a sharp frequency window with a width of less than $8 \mathrm{MHz}$ (1.73\%). Outside this range, the nonlinear resonance generator does not interact with the diseased tissues. Signals were identified and recorded as malignant or benign (adenoma or hyperplastic polyps), related to adenoma detection and colon rectal cancer. These findings were compared with those from colonoscopy with histologic confirmation [93] [94] [95] [96] [97], see Appendix 1, and Ap- 
pendix 2.

Also Terahertz molecular resonance measurements of cancer DNA supported the hypothesis. Terahertz waves can directly observe changes in DNA because the measured characteristic energies lie in the same frequency region. Aberrant methylation of DNA is a well-known carcinogenic mechanism and a common chemical modification of DNA. Resonance signals have been quantified to identify the types of cancer cells with a certain degree of DNA methylation. The measurements revealed the existence of molecular resonance fingerprints of cancer DNAs in the terahertz region [98], see Appendix 2.

\section{EM Field-Treatment and Biological Mechanisms}

PEMF therapy is able to modulate gene expression and protein synthesis interacting with specific DNA sequences within gene promoter regions [100]-[105]. According to Vadalà: PEMFs inhibit angiogenesis in tumor tissues, suppressing tumor vascularization and reducing tumor growth, as shown in vivo studies [100] [106]-[111] [117]. Treated groups showed slower tumor growth rate if compared with untreated control group, confirming that PEMF therapy can modulate the physiology and electrochemistry of cancer cells and influence cell membrane systems and mitosis. PEMFs induce various changes in membrane transport capacity, through impacting the osmotic potential, ionic valves and reduction in cellular stress factors, in addition to increases in the rate of DNA transcription, and modulation of immune response [100]. Studies show that specific EMF frequencies enhance skeletal stem cells, human bone marrow stromal cells adherence, proliferation, differentiation, and viability, all of which play also a key role in the use for tissue engineering [112]. The ability to interconvert information between electronic and ionic modalities has transformed the ability to record and actuate biological function. Electronic actuation of the native transcriptional regulators and transcription from promoters allows cell response that is quick, reversible and dependent on the amplitude and frequency of the imposed electronic signals [116].

\section{Potential Therapeutic Technologies to Prevent Cancer Due to Non-Coherent Radiation}

Different types of technologies have already been investigated to prevent detrimental biological effects of non ionizing radiation and even to induce beneficial biological effects. In the nineties, Litovitz and colleagues discovered that adding signals of electromagnetic noise to incoherent man made signals result in reduced detrimental biological effects. Litovitz showed a requirement for typical coherence times and types of modulations of an applied electromagnetic signals at ELF or microwave to enhance ornithine decarboxylase activity in L929 fibroblasts. Microwave fields, amplitude modulated (AM) by an extremely low-frequency (ELF) sine wave, induced a nearly twofold enhancement in the activity of ornithine decarboxylase (ODC) in L929 cells at SAR levels of the or- 
der of $2.5 \mathrm{~W} / \mathrm{kg}$. A second technology might be the application of so called trans-material catalysts [99] that are nano- and micron semiconductors able to add preferred coherent condensate signals to electromagnetic man made signals. A third promishing technology makes use of nanosecond PEMF that applies pulsed coherent frequencies using EM probe devices. The effectiveness of time varying electromagnetic fields on biological systems has been shown and depends on pulse design, frequency, duration, and magnetic field/rise time $(\mathrm{dB} / \mathrm{dt})$ [113] [115].

Improved PEMF-technologies and semiconducting nanomaterials will come available to generate coherent signals to state of the art electromagnetic signals focussing on stabilization of eigen-frequencies characteristic for functioning of living cells. Even beneficial EM signals can be integrated into man made communication instruments that either may neutralize adverse radiation modalities or even may be technically integrated in the many other electronic devices in daily practice, in order to create a healthy EM environment in the vicinity of our body [13] [118] [119] [120] [121].

\section{General Discussion of Overall Results}

We have previously shown that about 200 typical coherent EM-frequencies sustain the viability of living cells, and that the particular values are precisely positioned in, so called, coherent frequency bands. Exposure to about 150 typical non-coherent EM frequencies, produce unhealthy cells and turned out to be precisely positioned in the non-coherent frequency bands. The particular bands, that presumably represent soliton frequency zones, show a discrete distribution pattern, if plotted on an acoustic standing wave scale, called a semi-harmonic reference GM-scale (Figure 2). The distribution pattern shows a clear separation of the bands in a statistically significant manner. The pattern of twelve basic frequency intervals and bands could be adequately described by an acoustic algorithm. We regard this dicrete pattern of wave activities as a morphogenetic code, indicating a semi-harmonic vibration modality [12] [13].

Many published data now support the hypothesis that cancer can be initiated and promoted at typical frequencies of electromagnetic waves. The reported frequencies are apparently positioned in the same decoherent soliton frequency zones identified by us. In contrast, according to these studies, cancer can be inhibited and retarded in the discrete coherent soliton frequency zones inferred from our studies (Figure 3). The particular results are rather striking: nearly all (96.2\%) of the analysed 100 different EM continuous wave frequency data showed the cancer initiation/promotion or inhibition/retardation characteristics according to the proposed algorithm and fully support the present hypothesis.

With regard to the specific cancer-directed studies, in total 65 frequency data analysed, showed inhibition/retardation of cancer are shown to be presicely located in zones of coherent frequencies at a mean distance value around a coherent frequency of $0.79 \%$. The other analysed 35 frequency data, showing initia- 
tion/promotion of cancer, are positioned in zones of decoherent frequencies at a mean distance value from a coherent frequency of $1.66 \%$.

The particular beneficial, versus the detrimental EM frequencies zones, that are mirrored by oscillations in the intact cell, are features of a either a healthy state or a corrupted cell state. As listed in the 123 cases in Appendix 2, the dominant biological phenomena also obey to the proposed algorithmic soliton frequencies: They include cell differentiation, genome-wide methylation and the expression of DNA, DNA strand breaks, chromosomal aberrations, genetic expressions, foci in differentiated cells, oxidative damage, stem cells, neurons, plasma membranes, germ cells, reproductive system, cognitive effects, signalling path ways, learning and spatial memory, DNA damage, and apoptotic cell death. Of the overall studies, biological phenomena of healthy living cells are positioned in zones of beneficial coherent soliton frequencies, at a mean distance value around a coherent frequency of $0.78 \%$ (for continuous wave exposures), whereas unhealthy living cells are located in zones of detrimental decoherent soliton frequencies at a mean distance value from a coherent frequency of $1.86 \%$ (for continuous wave exposures).

Interestingly, in the investigations into the influence of EM frequencies that potentially induce cancer disorders, as listed in the Appendix 1, as much as 39 different values of electromagnetic waves make use of so called carrier waves that in our scheme in fact represent coherent soliton frequency bands, but of which the applied wave modulations that are superposed on the particular carrier waves belong, in contrast, to the decoherent soliton frequency bands. These kind of complex superposed waves therefore show an overall decoherent behaviour, resulting in detrimental biological properties. According to our calculations the overall mean distance from the respective coherent frequencies of these kind of waves amounts to $1.80 \%-2.00 \%$ and therefore, in our definition, therefore become highly incoherent.

It is further remarkable that living cells remain viable over a wide regime of electromagnetic wave radiations, with typical frequencies and modulations, and all are fitting into an electromagnetic range of frequencies, from about less than one Hertz till one peta Hertz $\left(10^{15}\right)$. In addition, the idea of selective zones of life/supporting or life endangering frequencies, was supported both by direct tissue measurements of typical endogeneous EM frequencies in healthy tissues, as opposed to endogeneous frequencies in cells with cancer features.

In general, the present study highlights the existence of a dominant vibrational spectrum of EM fields that, as an "algorithm of living cells", also may have played an evolutionary role in the initiation of first life and in the stabilization of life systems, until today. At the same time this principle of physics, as defined in our recent papers, can influence our health if the nature of the coherent frequencies is perturbed so that non-coherent frequencies, that is of sufficient density and exposure times, take over. With this knowledge it will be possible to develop innovative technologies that can effectively improve the life-sustaining coherency of electromagnetic signals. 


\section{Potential mechanisms of EMF in cancer disorders}

The mechanisms behind the life-sustaining and life-disturbing field effects of the spectrum of externally applied EM frequencies (including some directly measured values in normal and diseased tissues), as reported in the biomedical publications analyzed by us, can in principle be described on the basis of current biophysics:

The particular EM frequencies resonate with discrete vibratory macromolecules in the cell, producing domains of coherent wave patterns in proteins, cell water and/or DNA (Del Giudice [6]; Fröhlich [1]; Pang et al. [122]; Meijer and Geesink [14]; Melkikh and Meijer [121]). Coherence is seen by us a fundamental property of quantum biology and can be defined as the physical congruence of wave properties within wave packets and is a property of stationary waves (i.e. temporally and spatially constant) that enables a type of wave interference, known as constructive. This can lead to stabilizing internal vibratory patterns crucial for life conditions, as may have also been selected in biological evolution. Thereby, these waves are instrumental in beneficial influences on cell metabolism, intercellular information transfer and morphogenetic stimuli. Such coherent vibration patterns can also explain the long-range interactions between distant cell groups, as reviewed by Cifra [81]. We have earlier reported on the potential effects of solitons on protein folding as a long range mechanism [121]. The detrimental frequencies, detected by us, may cause non-coherent resonance by destructive resonant interference. It should be stipulated here that the life disturbing frequencies found were called by us non-coherent, yet this should not be confused with the term decoherence as the loss of quantum coherence due to interaction with the environment. The supposed coherent wave patterns (see Fröhlich, [1]), and dual (symmetric) wave/matrix interactions (see Pang et al. [122]) have been demonstrated by spectroscopic methods among others in proteins (Lundholm [5]; Bandyopadhyay [125]). The particular wave modalities could both have a quantum and classical character, the latter if sufficient cellular energy is supplied (Nardecchia et al. [123]).

The experimentally applied EM fields of the analyzed studies may mimic naturally occurring, terrestrial electro-magnetic patterns of the atmosphere and typical minerals present in the top-layer of the earth, probably including pre-mordial modalities, that have influenced the informational and structural organization of pre-biotic and first life cells as well as in in present life organisms (Melkikh and Meijer [121]; Melkikh, [124]). As discussed in our previous work [13] [14] [118] [119], especially polarized and cyclotron-like waves can directly perturb ion-channel proteins as demonstrated for $\mathrm{Ca}^{2+}$, an ion that is central in cell regulation.

\section{State of Art of EMF Therapy and Further Perspectives}

The field of EMF treatment of cancer disorders is rapidly expanding [127]-[173]. Recently a large number of in vitro and in vivo studies were published on the an- 
ticancer effects of alternating electromagnetic fields, that included low-intensity intermediate frequency $(100-300 \mathrm{KHz})$ alternating electric fields, as well as amplitude-modulated electromagnetic fields (EMF) of lower frequencies $(0.1 \mathrm{~Hz}$ to $120 \mathrm{KHz}$, see [105] [129]. As recently reviewed by Zimmerman et al. [43] such studies may show that anticancer effects at modulation frequencies specific for the cancer cell type or more general anti-cancer effects following exposure to alternating electric fields. They examined the growth rate of human tumor cell lines from liver and breast cancers along with normal cells from those tissues exposed to AM-EMF. Reduced growth rate might observed for tumor cells exposed to tissue-specific AM-EMF, in comparison with normal cells.

One study provided some evidence that adding tumor-specific frequencies (such as $27.12 \mathrm{Mhz}$ and amplitude-modulated at tumor-specific frequencies) may block proliferation of cancer cells both in vitro as well as in vivo at levels of exposure similar to those yielding therapeutic responses in humans, in an elegant approach [43]. There is preliminary evidence that adding tumor-specific frequencies (such as $1873.5 \mathrm{~Hz}, 2221.3 \mathrm{~Hz}, 6350.3 \mathrm{~Hz}$ and $10456.4 \mathrm{~Hz}$ ) may yield disease stabilization in patients according to these experiments [126]. An earlier study in 2009, provided some evidence that adding tumor-specific frequencies (such as $27.1 \mathrm{MHz}$ and $1873.5 \mathrm{~Hz}, 2221.3 \mathrm{~Hz}, 5882.3 \mathrm{~Hz}, 6350.3 \mathrm{~Hz}, 8452.1 \mathrm{~Hz}$, $10456.4 \mathrm{~Hz}$ ) may block proliferation of cancer cells both in vitro as well as in vi$v o$ at levels of exposure similar to those yielding therapeutic responses in humans [158]. However the applied frequencies are located at the non-coherent frequencies described by the present GM-scale. Methodological differences (direct measurement in cancer tissues versus our meta-analyses of biomedical literature) may be at stake. Yet we found several studies with direct tissue measurements in line with our GM algorithm (see section 6). Furthermore our GM-analysis shows that a more robust treatment might be realised by applying multiple coherent frequencies according to the proposed coherent frequency scale.

Interestingly, Cosic's Resonant Recognition Model (RRM) postulates that biological processes/interactions are based on electromagnetic resonances between interacting biomolecules at specific electromagnetic frequencies. This model approach deals with the infra-red, visible and ultra-violet frequency ranges, where each interaction can be identified by a certain frequency critical for resonant activation of specific biological activities of proteins and DNA [159]. The various biological interactions could be grouped according to their resonant frequency into super families of these functions, enabling simpler analyses of these interactions and consequently the analyses of influence of electromagnetic frequencies to health. According to Cosic, the RRM spectrum of all analyzed biological functions/interactions is similar to the spectrum of the sunlight on the Earth. The relative differences between the mean values of the proposed RRM spectrum between interacting biomolecules at specific electromagnetic frequencies and the mean frequency values of our algorithmic GM-scale for various life systems in vitro and in vivo amount to $2 \%$ or higher. The latter points to a statistical dif- 
ference that, according to our criteria, is too large to find an apparent correspondence between both models. Yet, a more systematic comparison of the respective data would be attractive.

Extremely low frequency (ELF) pulsed-gradient magnetic fields, not only induce changes in cell cycling [105]), but also may seem to block neovascularization required for tumour growth [153]). Cameron et al. [130] [131] showed that gamma irradiation IR or EMF therapy in mice had fewer lung metastatic sites and slower tumor growth, compared with controls.

\section{Preliminary clinical work}

Preliminary clinical results in various tumour types such as recurrent glioblastoma's, hepatocellular carcinomas and breast carcinomas showed perspectives. Many studies focused on low-frequency $(<300 \mathrm{~Hz})$ magnetic fields with simple or symmetrical (sine- or square-wave) patterns to affect cellular processes. Some studies have shown that exposure to a low frequency EMF pattern can promote cell proliferation while others have shown that EMF exposure inhibits cell proliferation, in line with the present study. EMF therapies may reduce proliferation and induce apoptosis in different cancer cells such as osteosarcoma, breast cancer, gastric cancer, colon cancer, and melanoma. Marchesi et al. [145] showed that autophagy is induced upon EMF exposure in neuroblastoma cells and also tumor vascularization can be inhibited in vitro and in vivo in breast cancer. EMF therapy decreased tumor growth in mouse models of malignant melanoma, colon carcinoma and adenocarcinoma. Costa et al. [135] showed clear clinical benefits from using the specific AM-EMF signals to treat advanced hepatocellular carcinoma, also with partial responses up to 5 years in some of the patients.

\section{Potential mechanisms and types of EMF exposure}

Exposure of cells to 20 - $60 \mathrm{~Hz}$ EMF patterns has further been shown to affect signal transduction pathways with effects on cAMP levels, MAP kinase activation, $\mathrm{Ca}^{2+}$-calmodulin kinase activation, or $\mathrm{Ca}^{2+}$ channels [102] [129]. It is important to note that the inhibitory response can be strongly field-strength and exposure-time dependent. It was hypothesized by Buckner et al., [129], that the ability of EMFs to interact with biological processes is dependent on the temporal patterns of the fields, similar to the way anti-cancer agents are dependent on their structures. Therefore, the information chosen in a specific time-varying pattern, also at low intensities $(5-10 \mu \mathrm{T})$, could influence biological processes. The characteristics of an EMF that elicit biological responses should be specific for wave pattern, field strength, and exposure configuration. Barbault et al. [126] reported on specific frequencies for different tumour diagnoses, which are then used in the amplitude-modulated (AM)-EMF treatment of those patients to stabilize the disease beyond normal expectations.

\section{Combination of EMF with radio and chemotherapy}

Various studies [132] [153]-[160] showed the potential of EMF therapy in combination with conventional cancer therapies as new approach for sensitizing tumors. Also here, the applied EMF patterns show great differences in intensity, 
direction and frequency as well as wave forms, ranging from sinusoidal to square-wave to pulsed-wave forms across studies. Baharara et al. showed that extremely low EMF therapy restored the sensitivity of cisplatin resistant human ovarian carcinoma cells by increased apoptosis rates. In combination with radiotherapy, EMF improved survival of mice bearing hepatoma as compared with EMF or radiotherapy alone. Similarly, Cameron et al. [130] showed this for breast cancer xenografts including decreased lung metastasis.

\section{Perspectives from the present study}

It is hoped that the distinct pattern of beneficial and detrimental EM frequencies, as consistantly shown in our studies, may invite further experimental and clinical studies in which systematically various potential treatment protocols could be applied to obtain even more efficient EMF anti-cancer therapies. Not only proper combinations of multiple selective EM frequencies (either modulated on carrier waves or as such), that could be simultaneously or sequentially applied, but also sensitizing tumor tissue for conventional therapies with EMF in various frequency regions would be of great interest. As mentioned above, our observations can also lead to the innovative design of nano-protectve materials for protective purposes.

\section{Relevant Conflicts of Interest/Financial Disclosures}

The authors declare that the research was conducted in the absence of any commercial or financial relationships that could be construed as a potential conflict of interest.

\section{References}

[1] Fröhlich, H. (1988) Biological Coherence and Response to External Stimuli. Springer, Berlin, Heidelberg, New York. https://doi.org/10.1007/978-3-642-73309-3

[2] Lawrence, A.F. and Adey, W.R. (1982) Non-Linear Wave Mechanisms in Interaction between Excitable Tissue and Electromagnetic Fields. Neurological Research, 4, 115-154. https://doi.org/10.1080/01616412.1982.11739619

[3] Adey, W.R. and Lawrence, A.F. (1984) Nonlinear Dynamics in Biological Systems. Plenum Press, New York.

[4] Preto, J. (2016) Classical Investigation of Long-Range Coherence in Biological Systems. Journal of Nonlinear Science, 26. https://doi.org/10.1063/1.4971963

[5] Lundholm, I.V., Rodilla, H., Wahlgren, W.Y., Duelli, A., Bourenkov, G., Vukusic, .J, Friedman, R., Stake, J., Schneider, T. and Katona, G. (2015) Terahertz Radiation Induces Non-Thermal Structural Changes Associated with Fröhlich Condensation in a Protein Crystal. Structural Dynamics, 13, 054702. https://doi.org/10.1063/1.4931825

[6] Del Giudice, E., Spinetti P.S. and Tedeschi A. (2010) Water Dynamics at the Root of Metamorphosis in Living Organisms. Water, 2, 566-586. https://doi.org/10.3390/w2030566

[7] Chaplin, M.F. (2000) A Proposal for the Structuring of Water. Biophysical Chemistry, 24, 211-221. https://doi.org/10.1016/S0301-4622(99)00142-8

[8] Johnson, K. (2009) "Water Buckyball” Terahertz Vibrations in Physics, Chemistry, 
Biology, and Cosmology.

[9] Semikhina, L.P., Kiselev, V.F., Levshin, L.V. and Saletskii, A.M. (1988) Effect of Weak Magnetic Fields on the Luminescence-Spectral Properties of a Dye in an Aqueous Solution. Journal of Applied Spectroscopy, 48, 556-559. https://doi.org/10.1007/BF00663473

[10] Semikhina, L.P., Kiselev, V.F. (1981) Effect of Weak Magnetic Fields on the Properties of Water and Ice. Russian Physics Journal, 31, 5351-5354.

[11] Henry, M. (2016) Hofmeister Series: The Quantum Mechanical Viewpoint. Current Opinion in Colloid \& Interface Science, 23, 119-125.

https://doi.org/10.1016/j.cocis.2016.08.001

[12] Geesink, J.H. and Meijer, D.K.F. (2016) Quantum Wave Information of Life Revealed: An Algorithm for EM Frequencies That Create Stability of Biological Order, with Implications for Brain Function and Consciousness. NeuroQuantology, 14, 106-125. https://doi.org/10.14704/nq.2016.14.1.911

[13] Geesink, J.H. and Meijer, D.K.F. (2017) Bio-Soliton Model that Predicts Non-Thermal Electromagnetic Frequency Bands, that Either Stabilize Living Cells. Electromagnetic Biology and Medecine, 36, 357-378. https://doi.org/10.1080/15368378.2017.1389752

[14] Meijer, D.K.F. and Geesink, J.H. (2016) Phonon Guided Biology: Architecture of Life and Conscious Perception Are Mediated by Toroidal Coupling of Phonon, Photon and Electron Information Fluxes at Discrete Eigenfrequencies. NeuroQuantology, 14, 718-755. https://doi.org/10.14704/nq.2016.14.4.985

[15] Shor, P.W. (1997) Polynomial-Time Algorithms for Prime Factorization and Discrete Logarithms on a Quantum Computer. SIAM Journal on Computing, 26, 1484-1509. https://doi.org/10.1137/S0097539795293172

[16] Plankar, M., Jerman I. and Krasovec, R. (2011) On the Origin of Cancer: Can We Ignore Coherence? Progress in Biophysics and Molecular Biology, 106, 380e390.

[17] Sonnenschein, C. and Soto, A.M. (2008) Theories of Carcinogenesis: An Emerging Perspective. Seminars in Cancer Biology, 18, 372e377. https://doi.org/10.1016/j.semcancer.2008.03.012

[18] Sonnenschein, C., Davis, B. and Soto, A.M. (2014) A Novel Pathogenic Classification of Cancers. Cancer Cell International, 14, 113e117.

[19] Pokorný, J., Pokorný, J., Foletti, A., Kobilková, J., Vrba, J. and Vrba, J. (2015) Mitochondrial Dysfunction and Disturbed Coherence: Gate to Cancer. Pharmaceuticals, 8, 675-695. https://doi.org/10.3390/ph8040675

[20] Levin, M. (2003) Bioelectromagnetics in Morphogenesis. Bioelectromagnetics, 24, 295-315. https://doi.org/10.1002/bem.10104

[21] Levin, M. (2012) Morphogenetic Fields in Embryogenesis, Regeneration, and Cancer: Non-local Control of Complex Patterning. BioSystems, 109, 243-261. https://doi.org/10.1016/j.biosystems.2012.04.005

[22] Chernet, B. and Levin, M. (2013) Endogenous Voltage Potentials and the Microenvironment: Bioelectric Signals that Reveal, Induce and Normalize Cancer. Journal of Clinical \& Experimental Oncology, S1, S1-002.

[23] Knox, S.S. and Funk, R.H.W. (2014) Oncology and Biophysics: A Need for Integration. Knox and Funk. Journal of Clinical \& Experimental Oncology, S1.

[24] Maziarz, A., Kocan, B., Bester, M., Budzik, S., Cholewa, M., Ochiya, T. and Banas, A. (2016) How Electromagnetic Fields Can Influence Adult Stem Cells: Positive and Negative Impacts. Stem Cell Research \& Therapy, 7, 54. 
https://doi.org/10.1186/s13287-016-0312-5

[25] Tuszynski, J.A., Wenger, C., Friesen, D.E. and Preto J. (2016) An Overview of Sub-Cellular Mechanisms Involved in the Action of TTFields. International Journal of Environmental Research and Public Health, 13, 1128. https://doi.org/10.3390/ijerph13111128

[26] Popp, F.A. (1976) Biophotonen-Ein neuer Weg zur Lösung des Krebsproblems. Verlag für Medizin Dr. Ewald Fischer, Heidelberg.

[27] Le Chapellier, P. and Matta, B. (2014) Is Victory over Pancreatic Cancer Possible, with the Help of Tuned Non-Invasive Physiotherapy? A Case Study Says Yes. Journal of Cancer Therapy, 5, 460-477. https://doi.org/10.4236/jct.2014.55053

[28] Gao, D., Li, S. (2013) Biological Resonance for Cancer Metastasis, a New Hypothesis Based on Comparisons between Primary Cancers and Metastases. Cancer Microenvironment, 6, 213-230. https://doi.org/10.1007/s12307-013-0138-y

[29] Belyaev, I.Y., Alipov, Y.D. and Shcheglov, V.S. (1992) Chromosome DNA as a Target of Resonant Interaction between Escherichia-Coli-Cells and Low Intensity Millimeter Waves. Electro- and Magnetobiology, 11, 97-108.

https://doi.org/10.3109/15368379209009820

[30] Belyaev, I.Y., Matronchik, A.Y. and Alipov, Y.D. (1994) Effect of Weak Static and Alternating Magnetic Fields on the Genome Conformational State of E. coli Cells: Evidence for the Model of Modulation of High Frequency Oscillations. In: Allen, M.J., Ed., Charge and Field Effects in Biosystems, World Scientific Publish. Co. PTE Ltd., Singapore, 174-184.

[31] Belyaev, I.Y., Shcheglov, V.S., Alipov, Y.D. and Polunin, V.A. (1996) Resonance Effect of Millimeter Waves in the Power Range from $10^{-19}$ to $3 \times 10^{-3} \mathrm{~W} / \mathrm{cm}^{2}$ on Escherichia coli Cells at Different Concentrations. Bioelectromagnetics, 17, 312-321. https://doi.org/10.1002/(SICI)1521-186X(1996)17:4<312::AID-BEM7>3.0.CO;2-6

[32] Belyaev, I.Y., Markovà, E., Hillert, L., Malmgren, L.O. and Persson, B.R. (2009) Microwaves from UMTS/GSM Mobile Phones Induce Long-Lasting Inhibition of 53BP1/Gamma-H2AX DNA Repair Foci in Human Lymphocytes. Bioelectromagnetics, 30, 129-141. https://doi.org/10.1002/bem.20445

[33] Belyaev, I. (2010a) Dependence of Non-Thermal Biological Effects of Microwaves on Physical and Biological Variables: Implications for Reproducibility and Safety Standards. In: Giuliani, L. and Soffritti, M., Eds., European Journal of Oncology-Library Non-Thermal Effects and Mechanisms of Interaction between Electromagnetic Fields and Living Matter. An ICEMS Monograph, Ramazzini Institute, Bologna, 187-218.

http://www.icems.eu/papers.htm?f=/c/a/2009/12/15/MNHJ1B49KH.DTL

[34] Belyaev, I.Y. (2015) Biophysical Mechanisms for Nonthermal Microwave Effects.

[35] Shcheglov, V.S., Belyaev, I.Y., Ushakov, V.L. and Alipov, Y.D. (1997b) Power-Dependent Rearrangement in the Spectrum of Resonance Effect of Millimeter waves on the Genome Conformational State of E. coli Cells. Electro- and Magnetobiology, 16, 69-82. https://doi.org/10.3109/15368379709016174

[36] Markova, E., Malmgren, L.O.G. and Belyaev, I.Y. (2010). Microwaves from Mobile Phones Inhibit 53BP1 Focus Formation in Human Stem Cells More Strongly than in Differentiated Cells: Possible Mechanistic Link to Cancer Risk. Environmental Health Perspectives, 118, 394-399.

[37] Litovitz, T.A., Krause, D., Penafiel, M., Elson, E.C. and Mullins, J.M. (1993) The Role of Coherence Time in the Effect of Microwaves on Ornithine Decarboxylase 
Activity. Bioelectromagnetics, 14, 395-403. https://doi.org/10.1002/bem.2250140502

[38] Litovitz, T.A., Penafiel, L.M., Farrel, J.M., Krause, D., Meister, R. and Mullins, J.M. (1997a). Bioeffects Induced by Exposure to Microwaves Are Mitigated by Superposition of ELF Noise. Bioelectromagnetics, 18, 422-430. https://doi.org/10.1002/(SICI)1521-186X(1997)18:6<422::AID-BEM4>3.0.CO;2-4

[39] Blackman, C.F. (1984) Sub-Chapter 5.7.5 Biological Effects of Low Frequency Modulation of RF Radiation. In: Elder, J.A. and Cahill, D.F., Eds., Biological Effects of Radiofrequency Radiation.

[40] Lai, H. and Singh, N.P. (1995) Acute Low-Intensity Microwave Exposure Increases DNA Single-Strand Breaks in Rat Brain Cells. Bioelectromagnetics, 16, 207-210. https://doi.org/10.1002/bem.2250160309

[41] Lai, H. and Singh, N.P. (1996) Single- and Double-Strand DNA Breaks in Rat Brain Cells after Acute Exposure to Radiofrequency Electromagnetic Radiation. International Journal of Radiation Biology, 69, 513-521. https://doi.org/10.1080/095530096145814

[42] Lai, H. (2004). Interaction of Microwaves and a Temporally Incoherent Magnetic Field on Spatial Learning in the Rat. Physiology \& Behavior, 82, 785-789. https://doi.org/10.1016/S0031-9384(04)00287-2

[43] Zimmerman, J.W., Jimenez, H., Pennison, M.J., Brezovich, I., Morgan, D., Mudry, A. Costa, F.P., Barbault, A. and Pasche, B. (2013) Targeted Treatment of Cancer with Radiofrequency Electromagnetic Fields Amplitude-Modulated at Tumor-Specific Frequencies. CACA Chinese Anti-Cancer Association 5.

[44] Beebe, S.J., Schoenbach, K.H. and Heller, R. (2010) Bioelectric Applications for Treatment of Melanoma. Cancers, 2, 1731-1770.

https://doi.org/10.3390/cancers2031731

[45] Persson, B.R., Bauréu, K.C., Grafstrom, G., Engstrom, P.E. and Salford, L.G. (2003) A Model for Evaluating Therapeutic Response of Combined Cancer Treatment Modalities: Applied to Treatment of Subcutaneously Implanted Brain Tumors (N32 and N29) in Fischer Rats with Pulsed Electric Fields (PEF) and 60Co-Gamma Radiation (RT). Technology in Cancer Research \& Treatment, 2, 459-470. https://doi.org/10.1177/153303460300200512

[46] Leone, L., Podda, M.V. and Grassi, C. (2015) Impact of Electromagnetic Fields on Stem Cells: Common Mechanisms at the Crossroad between Adult Neurogenesis and Osteogenesis. MINI REVIEW Published.

[47] Fröhlich, H. (1968) Long-Range Coherence and Energy Storage in Biological Systems. International Journal of Quantum Chemistry, 2, 641-652. https://doi.org/10.1002/qua.560020505

[48] Fröhlich, H. (1970) Long Range Coherence and the Action of Enzymes. Nature, 228, 1093. https://doi.org/10.1038/2281093a0

[49] Fröhlich, H. (1975) The Extraordinary Dielectric Properties of Biological Materials and the Action of Enzymes. Proceedings of the National Academy of Sciences, 72, 4211-4215. https://doi.org/10.1073/pnas.72.11.4211

[50] Fröhlich, H. (1977) Long-Range Coherence in Biological Systems. La Rivista del Nuovo Cimento, 7, 399-418. https://doi.org/10.1007/BF02747279

[51] Fröhlich, H. (1978) Coherent Electric Vibrations in Biological Systems and the Cancer Problem. IEEE Transactions on Microwave Theory and Techniques, 26, 613-618. https://doi.org/10.1109/TMTT.1978.1129446

[52] Fröhlich, H. (1980) The Biological Effects of Microwaves and Related Questions. In: 
Marton, L. and Marton, C., Eds., Advances in Electronics and Electron Physics, Academic Press, New York, 85-152. https://doi.org/10.1016/S0065-2539(08)60259-0

[53] Devyatkov, N.D. (1974) Influence of Millimetre Band Electromagnetic Radiation on Biological Objects. Sov Phys Usp, 16, 568-569. https://doi.org/10.1070/PU1974v016n04ABEH005308

[54] Devyatlov, N.D., Golant, M.V. and Betskii, O.V. (1991) Millimeter Waves and Their Role in Processes of Vital Activity (in Russian). Radio and Svyaz, Moscow.

[55] Devyatkov, N.D., Pletnyov, S.D., Chernov, Z.S., Faikin, V.V., et al. (1994) Effect of Low-Energy Nanosecond-Pulse EHF and Microwave Radiation with a Giant Peak Power on Biological Structures (Malignant Tumors). DAN SSSR, 336. (In Russian)

[56] Davydov, A.S. (1973) The Theory of Contraction of Proteins under Their Excitation. Journal of Theoretical Biology, 38, 559-569. https://doi.org/10.1016/0022-5193(73)90256-7

[57] Davydov, A.S. (1977) Solitons and Energy Transfer along Protein Molecules. Journal of Theoretical Biology, 66, 379-387. https://doi.org/10.1016/0022-5193(77)90178-3

[58] Frey, A.H. (1974) Differential Biologic Effects of Pulsed and Continuous Electromagnetic Fields and Mechanisms of Effect. Annals of the New York Academy of Sciences, 238, 273-279. https://doi.org/10.1111/j.1749-6632.1974.tb26796.x

[59] Adey, W.R. (1981) Ionic Nonequilibrium Phenomena. In: Illinger, K.H., Ed., Tissue Effects of Nonionizing Radiation, ACS Symposium Series, 271-297.

[60] Adey, W.R. (1990) Electromagnetic Fields, Cell Membrane Amplification, and Cancer Promotion, in Extremely Low Frequency Electromagnetic Fields. In: Wilson, B.W., Stevens, R.G. and Anderson, L.E., Eds., The Question of Cancer, Batelle Press, Columbus, OH, 211-249.

[61] Adey, W.R., et al. (1999) Spontaneous and Nitrosurea-Induced Primary Tumors of the Central Nervous System in Fischer 344 Chronically Exposed to $836 \mathrm{MHz}$ Modulated Microwaves. Radiation Research, 152, 293-302.

https://doi.org/10.2307/3580329

[62] Adey, W.R., Byus, C.V., Cain, C.D., Higgins, R.J., Jones, R.A., Kean, .CJ., Kuster, N., MacMurray, A., Stagg, R.B. and Zimmerman, G. (2000) Spontaneous and Nitrosourea-Induced Primary Tumors of the Central Nervous System in Fischer 344 Rats Exposed to Frequency-Modulated Microwave Fields. https://doi.org/10.1007/BF01878387

[63] Liboff, A.R. (1985) Geomagnetic Cyclotron Resonance in Living Cells. Journal of Biological Physics, 13, 99-102.

[64] Szmigielski, S., Lipski, M.B.S. and Sokolska, G. (1986) Immunologic and Cancer-Related Aspects of Exposure to Low-Level Microwave and Radiofrequency Fields. Department of Biological Effects of Nonionizing Radiation Center for Radiobiology and Radiation Safety Warsaw, Poland.

[65] Blank, M. and Soo, L. (2001) Electromagnetic Acceleration of Electron Transfer Reactions. Journal of Cellular Biochemistry, 81, 278-283. https://doi.org/10.1002/1097-4644(20010501)81:2<278::AID-JCB1042>3.0.CO;2-F

[66] Salford, L.G., Brun, A., Sturesson, K., Eberhardt, J.L. and Persson, B.R. (1994) Permeability of the Blood-Brain Barrier Induced by $915 \mathrm{MHz}$ Electromagnetic Radiation, Continuous Wave and Modulated at 8, 16, 50, and $200 \mathrm{~Hz}$. Microscopy Research and Technique, 27, 535-542. https://doi.org/10.1002/jemt.1070270608

[67] Binhi, V.N. (2002) Magnetobiology: Underlying Physical Problems. Academic 
Press, San Diego, CA, 473 p.

[68] Blackman, C.F., Benane, S.G., Rabinowitz, J.R., House, D.E. and Joines, W.T. (1985) A Role for the Magnetic Field in the Radiation-Induced Efflux of Calcium Ions from Brain Tissue in Vitro. Bioelectromagnetics, 6, 327-337. https://doi.org/10.1002/bem.2250060402

[69] Blackman, C.F., Blanchard, J.P., Benane, S.G. and House, D.E. (1996) Effects of ac and dc Magnetic Filed Orientation on Nerve Cells. Biochemical and Biophysical Research Communications, 220, 807-811. https://doi.org/10.1006/bbrc.1996.0485

[70] Carpenter, D.O., et al. (2010) Electromagnetic Fields and Cancer: The Cost of Doing Nothing. Reviews on Environmental Health, 25, 75-80.

https://doi.org/10.1515/REVEH.2010.25.1.75

[71] Belyaev, I.Y., Alipov, Y.D., Polunin, V.A. and Shcheglov, V.S. (1993) Evidence for Dependence of Resonant-Frequency of Millimeter-Wave Interaction with Escherichia-coli Kl2 Cells on Haploid Genome Length. Electro- and Magnetobiology, 12, 39-49. https://doi.org/10.3109/15368379309012861

[72] Belyaev, I.Y., Alipov, Y.D., Shcheglov, V.S. and Lystsov, V.N. (1992) Resonance Effect of Microwaves on the Genome Conformational State of E. coli Cells. Zeitschrift für Naturforschung $C$, 47, 621-627.

[73] Belyaev, I.Y., Alipov, Y.D., Shcheglov, V.S., Polunin, V.A. and Aizenberg, O.A. (1994) Cooperative Response of Escherichia-coli-Cells to the Resonance Effect of Millimeter Waves at Super Low-Intensity. Electro- and Magnetobiology, 13, 53-66. https://doi.org/10.3109/15368379409030698

[74] Belyaev, I.Y., Shcheglov, V.S. and Alipov, Y.D. (1992) Existence of Selection Rules on Helicity during Discrete Transitions of the Genome Conformational State of $E$. coli Cells Exposed to Low-Level Millimetre Radiation. Bioelectrochemistry and Bioenergetics, 27, 405-411. https://doi.org/10.1016/0302-4598(92)87015-M

[75] Belyaev, I.Y., Shcheglov, V.S. and Alipov, Y.D. (1992) Selection Rules on Helicity during Discrete Transitions of the Genome Conformational State in Intact and X-Rayed Cells of E. coli in Millimeter Range of Electromagnetic Field. Biosystems. Birkhauser, Basel, Switzerland, 115-126.

https://doi.org/10.1007/978-1-4615-9837-4_10

[76] Belyaev, I.Y., Shcheglov, V.S., Alipov, Y.D. and Radko, S.P. (1993) Regularities of Separate and Combined Effects of Circularly Polarized Millimeter Waves on E. coli Cells at Different Phases of Culture Growth. Bioelectrochemistry and Bioenergetics, 31, 49-63. https://doi.org/10.1016/0302-4598(93)86105-A

[77] Belyaev, I.Y. and Kravchenko, V.G. (1994) Resonance Effect of Low-Intensity Millimeter Waves on the chromatin Conformational State of Rat Thymocytes. Zeitschrift für Naturforschung $C$, 49, 352-358.

[78] Belyaev, I.Y., Markova, E. and Malmgren, L. (2010) Microwaves from Mobile Phones Inhibit 53BP1 Focus Formation in Human Stem Cells More Strongly Than in Differentiated Cells: Possible Mechanistic Link to Cancer Risk. Environmental Health Perspectives, 118, 394-399.

[79] Brizhik. L. and Cruzeiro-Hansson, E.A. (1998) Influence of Electromagnetic Radiation on Molecular Solitons. Journal of Biological Physics, 24, 19-39. https://doi.org/10.1023/A:1005096714234

[80] Brizhik, L., Eremko, A., Piette, B. and Zakrzewski, W. (2009) Effects of Periodic Electromagnetic Field on Charge Transport in Macromolecules. Electromagnetic Biology and Medicine, 28, 15-27. https://doi.org/10.1080/15368370802708223

[81] Cifra, M., Fields, J.Z. and Farhadi, A. (2010) Electromagnetic Cellular Interactions. 
Progress in Biophysics and Molecular Biology, 2010, 1-24.

[82] Cifra, M., Pokorný, J., Jelínek, F. and Kučera, O. (2009) Vibrations of Electrically Polar Structures in Biosystems Give Rise to Electromagnetic Field: Theories and Experiments. Proceedings of Progress in Electromagnetics Research Symposium 2009, Moscow, 18-21 August 2009, The Electromagnetics Academy, Cambridge, 138-142.

[83] Pokorný, J. (2011) Electrodynamic Activity of Healthy and Cancer Cells. Journal of Physics: Conference Series, 329, Article ID: 012007. https://doi.org/10.1088/1742-6596/329/1/012007

[84] Pokorný, J., Vedruccio, C., Cifra, M. and Kucera, O. (2011) Cancer Physics: Diagnostics Based on Damped Cellular Elastoelectrical Vibrations in Microtubules. $E u-$ ropean Biophysics Journal, 40, 747-759.

http://www.springerlink.com/content/577757274043rk07/ https://doi.org/10.1007/s00249-011-0688-1

[85] Pokorný, J., Jandová, A., Nedbalová, M., Jelínek, F., Cifra, M., Kučera, O., Havelka, D., Vrba, J., Vrba, J., Čoček, A. and Kobilková, J. (2012) Mitochondrial Metabolism-Neglected Link of Cancer Transformation and Treatment. Prague Medical Report, 113, 81-94. https://doi.org/10.14712/23362936.2015.24

[86] Srobar, F. (2009a) Occupation-Dependent Access to Metabolic Energy in Frohlich Systems. Electromagnetic Biology and Medicine, 28, 194-200. https://doi.org/10.1080/15368370802711862

[87] Srobar, F. (2009b) Role of Non-Linear Interactions by the Energy Condensation in Fröhlich Systems. Neural Netw World, 19, 361-368.

[88] Srobar, F. (2015) Radiating Fröhlich System as a Model of Cellular Electromagnetism. Electromagnetic Biology and Medicine, 34, 355-360. https://doi.org/10.3109/15368378.2014.934381

[89] Cosic, I., Cosic, D. and Lazar, K. (2015) Is It Possible to Predict Electromagnetic Resonances in Proteins, DNA and RNA? EPJ Nonlinear Biomedical Physics, 3, 5. https://doi.org/10.1140/epjnbp/s40366-015-0020-6

[90] Havas, M. (2017) When Theory and Observation Collide: Can Non-Ionizing Radiation Cause Cancer? Environmental Pollution, 221, 501-550. https://doi.org/10.1016/j.envpol.2016.10.018

[91] Barnes, F.S. and Greenebaum, B. (2014) The Effects of Weak Magnetic Fields on Radical Pairs. Bioelectromagnetics, 36, 45-54. https://doi.org/10.1002/bem.21883

[92] Longo, G., Montévil, M., Sonnenschein, C. and Soto, A.M. (2015) In Search of Principles for a Theory of Organisms. Journal of Biosciences, 40, 955-968.

https://doi.org/10.1007/s12038-015-9574-9

[93] Vedruccio, C. and Meessen, A. (2004) EM Cancer Detection by Means of Non Linear Resonance Interaction. Proceedings of the PIERS Progress in Electromagnetics Research Symposium, 28-31 March 2004, Pisa, 909-912.

[94] Vedruccio, C. and Vedruccio, C.R. (2011) Non Invasive Radiofrequency Diagnostics of Cancer. The Bioscanner-Trimprob Technology and Clinical Applications. Journal of Physics. Conference Series, 329, 012038. https://doi.org/10.1088/1742-6596/329/1/012038

[95] Dore, M.P., Tufano, M.O., Pes, G.M., Cuccu, M., Farina, V., Manca, A. and Graham, D.Y. (2015) Tissue Resonance Interaction Accurately Detects Colon Lesions: A Double-Blind Pilot Study. World Journal of Gastroenterology, 21, 7851-7859. https://doi.org/10.3748/wjg.v21.i25.7851

[96] Gervino, G., Autino, E., Kolomoets, E., Leucci, G. and Balma, M. (2007) Diagnosis 
of Bladder Cancer at $465 \mathrm{MHz}$. Electromagnetic Biology and Medicine, 26, 119-134. https://doi.org/10.1080/15368370701380850

[97] Fornes-Leal, A., Garcia-Pardo, C., Frasson, M., Pons, B. V. and Cardona, N. (2016). Dielectric Characterization of Healthy and Malignant Colon Tissues in the 0.5-18 GHz Frequency Band. Physics in Medicine and Biology, 61, 7334-7346. https://doi.org/10.1088/0031-9155/61/20/7334

[98] Cheon, H., Yang, H.-J., Lee, S.-H., Kim, Y.A. and Son, J.-H. (2016) Terahertz Molecular Resonance of Cancer DNA. Scientific Reports, 6, 37103. https://doi.org/10.1038/srep37103

[99] Bechmann, M., Steitz, M. and Klein, H. (2016) Zukunftstechnologie Transmateriale Katalysatoren.

[100] Vadalà, M., Morales-Medina, J.C., Vallelunga, A., Palmieri, B., Laurino, C. and Lannitti, T. (2016) Mechanisms and Therapeutic Effectiveness of Pulsed Electromagnetic Field Therapy in Oncology. Cancer Medicine, 5, 3128-3139. https://doi.org/10.1002/cam4.861

[101] Kirson, E.D., Dbaly, V., Tovarys, F., Vymazal, J., Soustiel, J.F., Itzhaki, A., et al. (2007) Alternating Electric Fields Arrest Cell Proliferation in Animal Tumor Models and Human Brain Tumors. Proceedings of the National Academy of Sciences, 104, 10152-10157. https://doi.org/10.1073/pnas.0702916104

[102] Crocetti, S., Beyer C., Schade, G., Egli, M., Frohlich, J. and Franco-Obregon, A. (2013) Low Intensity and Frequency Pulsed Electromagnetic Fields Selectively Impair Breast Cancer Cell Viability. PLoS One, 8, e72944. https://doi.org/10.1371/journal.pone.0072944

[103] Zimmerman, J.W., Pennison, M.J., Brezovich, I., Yi, N., Yang, C.T., Ramaker, R., et al. (2012) Cancer Cell Proliferation Is Inhibited by Specific Modulation Frequencies. British Journal of Cancer, 106, 307-313. https://doi.org/10.1038/bjc.2011.523

[104] Morabito, C.S., Guarnieri, S., Fano, G. and Mariggio, M.A. (2010) Effects of Acute and Chronic Low Frequency Electromagnetic Field Exposure on PC12 Cells during Neuronal Differentiation. Cellular Physiology and Biochemistry, 26,947-958. https://doi.org/10.1159/000324003

[105] Filipovic, N.D.T., Radovi,c M., Cvetkovic, D., Curcic, M., Markovic, S., Peulic, A., et al. (2014) Electromagnetic Field Investigation on Different Cancer Cell Lines. Cancer Cell International, 14, 1-10. https://doi.org/10.1186/s12935-014-0084-x

[106] Nuccitelli, R.U., Pliquett, X., Chen, W., Ford, R., Swanson, J., Beebe, S.J., et al. (2006) Nanosecond Pulsed Electric Fields Cause Melanomas to Self-Destruct. Biochemical and Biophysical Research Communications, 343, 351-360. https://doi.org/10.1016/j.bbrc.2006.02.181

[107] White, J.A., Blackmore, P.F., Schoenbach, K.H. and Beebe, S.J. (2004) Stimulation of Capacitative Calcium Entry in HL-60 Cells by Nanosecond Pulsed Electric Fields. The Journal of Biological Chemistry, 279, 22964-22972. https://doi.org/10.1074/jbc.M311135200

[108] Beebe, S.J., Blackmore, P.F., White, J., Joshi, R.P. and Schoenbach, K.H. (2004) Nanosecond Pulsed Electric Fields Modulate Cell Function through Intracellular Signal Transduction Mechanisms. Physiological Measurement, 25, 1077-1093. https://doi.org/10.1088/0967-3334/25/4/023

[109] Beebe, S.J., Fox, P.M., Rec, L.J., Willis, E.L. and Schoenbach, K.H. (2003) Nanosecond, High-Intensity Pulsed Electric Fields Induce Apoptosis in Human Cells. The FASEB Journal, 17, 1493-1495. https://doi.org/10.1096/fj.02-0859fje

[110] Nuccitelli, R., Chen X., Pakhomov, A.G., Baldwin, W.H., Sheikh, S., Pomicter, J.L., 
et al. (2009) A New Pulsed Electric Field Therapy for Melanoma Disrupts the Tumor's Blood Supply and Causes Complete Remission without Recurrence. International Journal of Cancer, 125, 438-445. https://doi.org/10.1002/ijc.24345

[111] Stupp, R., Taillibert, S., Kanner, A.A., et al. (2015) Maintenance Therapy with Tumor-Treating Fields plus Temozolomide vs Temozolomide Alone for Glioblastoma a Randomized Clinical Trial. JAMA, 314, 2511-2513.

https://doi.org/10.1001/jama.2015.16669

[112] Ross, C.L., Siriwardane, M., Almeida-Porada, G., Porada, C.D., Brink, P., Christ, G.J. and Harrison, B.S. (2015) The Effect of Low-Frequency Electromagnetic Field on Human Bone Marrow Stem/Progenitor Cell Differentiation. Stem Cell Research, 15, 96-108. https://doi.org/10.1016/j.scr.2015.04.009

[113] Madkan, A., Lin-Ye, A., Pantazatos, S.P., Geddis, M.S., Blank, M. and Goodman, R. (2009) Frequency Sensitivity of Nanosecond Pulse EMF on Regrowth and hsp70 Levels in Transected Planaria. J. Biomedical Science and Engineering, 2, 227-238. https://doi.org/10.4236/jbise.2009.24036

[114] Niggli, H.J., Tudisco, S., Lanzanò, L., Applegate, L.A., Scordino, A. and Musumeci, F. (2008) Laser-Ultraviolet-A induced Ultra Weak Photon Emission in Human Skin Cells: A Biophotonic Comparison between Keratinocytes and Fibroblasts. Indian Journal of Experimental Biology, 46, 358-363.

[115] Yamaguchi, S., Ogiue-Ikeda, M., Sekino M. and Ueno, S. (2006) Effects of Pulsed Magnetic Stimulation on Tumor Development and Immune Functions in Mice. Bioelectromagnetics, 27, 64-72. https://doi.org/10.1002/bem.20177

[116] Tschirhart, T., Kim, E., McKay, .R, Ueda, H., Wu, H-C., Pottash, A.E., Zargar, A., Negrete, A., Shiloach, J., Payne, G. and Bentley, W.E. (2017) Electronic Control of Gene Expression And Cell Behaviour in Escherichia coli through Redox Signalling. Nature Communications, 8, 14030. https://doi.org/10.1038/ncomms14030

[117] Giladi, M., Weinberg, U., Schneiderman, R.S., Porat, Y., Munster, M., Voloshin, T., Blatt, R., Cahal, S., Itzhaki, A., Onn, A., Kirson, E.D. and Paltia, Y. (2014) Alternating Electric Fields (Tumor-Treating Fields Therapy) Can Improve Chemotherapy Treatment Efficacy in Non-Small Cell Lung Cancer Both in Vitro and in Vivo. Seminars in Oncology, 41, S35-S41. https://doi.org/10.1053/j.seminoncol.2014.09.006

[118] Geesink, J.H. and Meijer, D.K.F. (2017) Electromagnetic Frequency Patterns That Are Crucial for Health and Disease Reveal a Generalized Biophysical Principle: The GM Scale. Quantum Biosystems, 8, 1-16. http://www.quantumbiosystems.org/eng/index.php?pagina $=5$

[119] Meijer, D.K.F. and Geesink, J.H., (2017). Consciousness in the Universe Is Scale Invariant and Implies the Event Horizon of the Human Brain. NeuroQuantology, 15, 41-79. https://www.neuroquantology.com/index.php/journal/article/viewFile/1079/852

[120] Geesink, J.H. and Meijer, D.K.F. (2017) Cancer Is Promoted by Cellular States of Electromagnetic Decoherence and Can Be Corrected by Exposure to Coherent Non-Ionizing Electromagnetic Fields. A Physical Model about Cell-Sustaining and Cell-Decaying Soliton Eigen-Frequencies. https://www.researchgate.net/publication/316058728_Cancer_is_promoted_by_cell ular_states_of_electromagnetic_decoherence and can be corrected by exposure to coherent non-ionizing electromagneticfields

[121] Melkikh, A.V. and Meijer, D.K.F. (2017) On a Generalized Levinthal's Paradox: The Role of Long- and Short Range Interactions on Complex Bio-Molecular Reactions, Including Protein and DNA Folding. Progress in Biophysics and Molecular Biology, 
132, 57-79. https://doi.org/10.1016/j.pbiomolbio.2017.09.018

[122] Pang, X.F., Chen, S., Wang, X. and Zhong, L. (2016) Influences of Electromagnetic Energy on Bio-Energy Transport through Protein Molecules in Living Systems and Its Experimental Evidence. International Journal of Molecular Sciences, 17, 1130. https://doi.org/10.3390/ijms17081130

[123] Nardecchia, I., Torres, J., Lechelon, M., Giliberti, V., Ortolani, M., Nouvel, P., Gori, M., Donato, I., Preto, J., Varani, L., Sturgis, J. and Pettini, M. (2017) Out-of-Equilibrium Collective Oscillation as Phonon Condensation in a Model Protein. https://arxiv.org/pdf/1705.07975.pdf

[124] Melkikh, A.V. (2014) Quantum Information and the Problem of Mechanisms of Biological Evolution. BioSystems, 115, 33-45. https://doi.org/10.1016/j.biosystems.2013.10.005

[125] Bandyopadhyay, A. (2013) Multi-level Memory-Switching Properties of a Single Brain Microtubule. Applied Physics Letters, 123701, 102-114.

[126] Barbault, A., Costa, F.P., Bottger, B., Munden, R.F., Bomholt, F. and Kuster, N. (2009) Amplitude-Modulated Electromagnetic Fields for the Treatment of Cancer: Discovery of Tumor-Specific Frequencies and Assessment of a Novel Therapeutic Approach. Journal of Experimental \& Clinical Cancer Research, 28, 51. https://doi.org/10.1186/1756-9966-28-51

[127] Besset, C.A. (1985) The Development and Application of Pulsed Electromagnetic Fields (PEMFs) for Ununited Fractures and Arthrodeses. Clinics in Plastic Surgery, 12, 259-277.

[128] Blackman, C.F. (2012) Treating Cancer with Amplitude-Modulated Electromagnetic Fields: A Potential Paradigm Shift, Again? British Journal of Cancer, 106, 241-242. https://doi.org/10.1038/bjc.2011.576

[129] Buckner, C.A., Buckner, A.L., Koren, S.A., Persinger, M.A. and Lafrenie, R.M. (2015) Inhibition of Cancer Cell Growth by Exposure to a Specific Time-Varying Electromagnetic Field Involves T-Type Calcium Channels. PLoS One, 10, e0124136. https://doi.org/10.1371/journal.pone.0124136

[130] Cameron, I.L, Markov, M.S. and Hardman, W.E. (2014) Optimization of a Therapeutic Electromagnetic Field (EMF) to Retard Breast Cancer Tumor Growth and Vascularity. Cancer Cell International, 14, 125. https://doi.org/10.1186/s12935-014-0125-5

[131] Cameron, I.L., Sun, L.-Z., Short, N., Hardman, W.E. and Williams, C.D. (2005) Therapeutic Electromagnetic Field (TEMF) and Gamma Irradiation on Human breast Cancer Xenograft Growth, Angiogenesis and Metastasis. Cancer Cell International, 5, 23. https://doi.org/10.1186/1475-2867-5-23

[132] Whissell, P.D. and Persinger, M.A. (2007) Emerging Synergisms between Drugs and Physiologically-Patterned Weak Magnetic Fields: Implications for Neuropharmacology and the Human Population in the Twenty-First Century. Current Neuropharmacology, 5, 278-288. https://doi.org/10.2174/157015907782793603

[133] Chenguo, Y., Yan, M., Xiaoqian, H., Chengxiang, L., Caixin, S., Junying, T., et al. (2008) Experiment and Mechanism Research of SKOV3 Cancer Cell Apoptosis induced by Nanosecond Pulsed Electric Field. 30th Annual International Conference of the IEEE Engineering in Medicine and Biology Society, 2008, 1044-1047.

[134] Chou, C.K. (1995) Radiofrequency Hyperthermia in Cancer Therapy. In The Biomedical Engineering Handbook. CRC Press, Boca Raton, FL, 1424-1430.

[135] Costa, F.P., de Oliveira, A.C., Meirelles, R., Machado, M.C.C., Zanesco, T., Surjan, 
R., Chammas, M.C., de Souza, R.M., Morgan, D., Cantor, A., Zimmerman, J., Brezovich, I., Kuster, N., Barbault, A. and Pasche, B. (2011) Treatment of Advanced Hepatocellular Carcinoma with Very Low Levels of Amplitude-Modulated Electromagnetic Fields. British Journal of Cancer, 105, 640-648.

https://doi.org/10.1038/bjc.2011.292

[136] Delle Monache, S., Angelucci, A., Sanità, P., Iorio R., Bennato, F., Mancini, F., et al. (2013) Inhibition of Angiogenesis Mediated by Extremely Low-Frequency Magnetic Fields (ELF-MFs). PLoS ONE, 8, e79309. https://doi.org/10.1371/journal.pone.0079309

[137] Destefanis, M., Viano, M., Leo, C., Gervino, G., Ponzetto, A. and Silvagno, F. (2015) Extremely Low Frequency Electromagnetic Fields affect Proliferation and Mitochondrial Activity of Human Cancer Cell Lines. International Journal of Radiation Biology, 91, 964-972. https://doi.org/10.3109/09553002.2015.1101648

[138] Elson, E.I. (1995) Biologic Effects of Radiofrequency and Microwave Fields in Vivo and in Vitro Experimental Results. In: Bronzino, J.D., Ed., The Biomedical Engineering Handbook, CRC Press, Boca Raton, FL., 1417-1423.

[139] Elson, E.I. (2009) The Little Explored Efficacy of Magnetic Fields in Cancer Treatment and Postulation of the Mechanism of Action. Electromagnetic Biology and Medicine, 28, 275-282.

[140] Harris, P.A., Lamb, J., Heaton, B. and Wheatley, D.N. (2002) Possible Attenuation of the G2 DNA Damage Cell Cycle Checkpoint in HeLa Cells by Extremely Low Frequency (ELF) Electromagnetic Fields. Cancer Cell International, 2, 3. https://doi.org/10.1186/1475-2867-2-3

[141] Holzapfel, C., Vienken, J., Zimmermann, U. (1982) Rotation of Cells in an Alternating Electric Field: Theory and Experimental Proof. The Journal of Membrane Biology, 67, 13-26. https://doi.org/10.1007/BF01868644

[142] Hu, J.H., St-Pierre, L.S., Buckner, C.A., Lafrenie, R.M. and Persinger, M.A. (2010) Growth of Injected Melanoma Cells Is Suppressed by Whole Body Exposure to Specific Spatial-Temporal Configurations of Weak Intensity Magnetic Fields. International Journal of Radiation Biology, 86, 79-88. https://doi.org/10.3109/09553000903419932

[143] Marchesi, N., Osera, C., Fassina, L., Amadio, M., Angeletti, F., Morini, M., et al. (2014) Autophagy Is Modulated in Human Neuroblastoma Cells Through Direct Exposition to Low Frequency Electromagnetic Fields. Journal of Cellular Physiolo$g y, 229,1776-1786$. https://doi.org/10.1002/jcp.24631

[144] Miao, X., Yin, S., Shao, Z., Zhang, Y. and Chen, X. (2015) Nanosecond Pulsed Electric Field Inhibits Proliferation and Induces Apoptosis in Human Osteosarcoma. J Orthop Surg Res., 10, 104. https://doi.org/10.1186/s13018-015-0247-Z

[145] Pawlowski, P., Szutowicz, I., Marszalek, P. and Fikus, M. (1993) Bioelectrorheological Model of the Cell. 5. Electrodestruction of the Cellular Membrane in Alternating Electrical Field. Biophys J, 65, 541-549. https://doi.org/10.1016/S0006-3495(93)81056-7

[146] Polk, C. (1995) Therapeutic Applications of Low-Frequency Sinusoidal and Pulsed Electric and Magnetic Fields. In: Bronzino, J.D., Ed., The Biomedical Engineering Handbook, CRC Press, Boca Raton, FL, 1404-1406.

[147] Reubold, T.F. and Eschenburg, S. (2012) A Molecular View on Signal Transduction by the Apoptosome. Cellular Signalling, 24, 1420-1425. https://doi.org/10.1016/j.cellsig.2012.03.007

[148] Silva, C.P., Oliveira, C.R. and Lima, M.C.P. (1996) Apoptosis as a Mechanism of 
Cell Death Induced by Different Chemotherapeutic Drugs in Human leukemict-Lymphocytes. Biochemical Pharmacology, 51, 1331-1340. https://doi.org/10.1016/0006-2952(96)00041-X

[149] Tofani, S., Barone, D., Cintorino, M., De Santi, M.M., Ferrara, A., Orlassino, R., et al. (2001) Static and ELF Magnetic Fields Induce Tumor Growth Inhibition and Apoptosis. Bioelectromagnetics, 22, 419-428. https://doi.org/10.1002/bem.69

[150] Walther, M., Mayer, .F, Kafka, W. and Schuetze, N. (2007) Effects of Weak, Low-Frequency Pulsed Electromagnetic Fields (BEMER Type) on Gene Expression of Human Mesenchymal Stem Cells and chondrocytes: An in Vitro Study. Electromagnetic Biology and Medicine, 26, 179-190. https://doi.org/10.1080/15368370701580814

[151] Wen, J., Jiang, S. and Chen, B. (2011) The Effect of $100 \mathrm{~Hz}$ Magnetic Field Combined with X-Ray on Hepatomaimplanted Mice. Bioelectromagnetics, 32, 322-324.

[152] Zhang, X., Zhang, H., Zheng, C., Li, C., Zhang, X. and Xiong, W. (2002) Extremely Low Frequency (ELF) Pulsed-Gradient Magnetic Fields Inhibit Malignant Tumour Growth at Different Biological Levels. Cell Biology International, 26, 599-603. https://doi.org/10.1006/cbir.2002.0883

[153] Artacho-Cordoan, F., Del Salinas-Asensio, M., Calvente, I., Rios-Arrabal, S., Leoan, J., Romaan-Marinetto, E., et al. (2013) Could Radiotherapy Effectiveness be Enhanced by Electromagnetic Field Treatment? International Journal of Molecular Sciences, 14, 14974-14995.

[154] Baharara, J., Hosseini, N. and Farzin, T.R. (2016) Extremely Low Frequency Electromagnetic Field Sensitizes Cisplatinresistant Human Ovarian Adenocarcinoma Cells via P53 Activation. Cytotechnology, 68, 1403-1413. https://doi.org/10.1007/s10616-015-9900-y

[155] Eke, I., Schneider, L., Forster, C., Zips, D., Kunz-Schughart, L.A. and Cordes, N. (2013) EGFR/JIP-4/JNK2 Signaling Attenuates Cetuximab-Mediated Radiosensitization of Squamous Cell Carcinoma Cells. Cancer Research, 73, 297-306.

[156] Ruiz-Goamez, M.J., De La Peña, L., Prieto-Barcia, M.I., Pastor J.M., Gil, L. and MartõÂnez-Morillo, M. (2002) Influence of 1 and $25 \mathrm{~Hz}, 1.5 \mathrm{mT}$ Magnetic Fields on Antitumor Drug Potency in a Human Adenocarcinoma Cell Line. Bioelectromagnetics, 23, 578-585.

[157] Storch, K., Dickreuter, E., Artati, A., Adamski, J. and Cordes, N. (2016) BEMER Electromagnetic Field Therapy Reduces Cancer Cell Radioresistance by Enhanced ROS Formation and Induced DNA Damage. PLOS ONE, 11, e0167931. https://doi.org/10.1371/journal.pone.0167931

[158] Pasche, B. (2009) Diagnosis and Treatment of Cancer with Very Low Levels EMFs Modulated at Tumor-Specific Frequencies. Journal of Experimental \& Clinical Cancer Research, 28, 51.

[159] Cosic, I., Cosic, D. and Lazar, K. (2016) Environmental Light and Its Relationship with Electromagnetic Resonances of Biomolecular Interactions, as Predicted by the Resonant Recognition Model. International Journal of Environmental Research and Public Health, 13, pii: E647. https://doi.org/10.3390/ijerph13070647

[160] Berg, H., Gunther, B., Hilger, I., Radeva, M., Traitcheva, N. and Wollweber, L. (2010) Bioelectromagnetic Field Effects on Cancer Cells and Mice Tumors. Electromagn. Biol. Med., 29, 132-143. https://doi.org/10.3109/15368371003776725

[161] Chen, X., Swanson, J. R., Kolb, J.F., Nuccitelli, R., Schoenbach K.H. (2009) Histopathology of Normal Skin And Melanomas after Nanosecond Pulsed Electric Field Treatment. Melanoma Research, 19, 361-371. 
https://doi.org/10.1097/CMR.0b013e32832f1558

[162] Crocetti, S., Piantelli, F. and Leonzio, C. (2011) Selective Destabilization of Tumor Cells with Pulsed Electric and Magnetic Sequences: A Preliminary Report. Electromagn. Biol. Med., 30, 128-135. https://doi.org/10.3109/15368378.2011.596247

[163] Nuccitelli, R., et al. (2010) Optimized Nanosecond Pulsed Electric Field Therapy Can Cause Murine Malignant Melanomas to Self-Destruct with a Single Treatment. International Journal of Cancer, 127, 1727-1736. https://doi.org/10.1002/ijc.25364

[164] Fang, M., Zhang, H. and Xue, S. (1998) Role of Calcium in Apoptosis of HL-60 Cells Induced by Harringtonine. Science in China Series C: Life Sciences, 41. https://doi.org/10.1007/BF02882901

[165] Kirson, E.D., Gurvich, Z., Schneiderman, R., Dekel, E., Itzhaki, A., Wasserman, Y., et al. (2004) Disruption of Cancer Cell Replication by Alternating Electric Fields. Cancer Research, 64, 3288-3295. https://doi.org/10.1158/0008-5472.CAN-04-0083

[166] Koh, E.K., Ryu, B.K., Jeong D.Y., Bang, I.S., Nam, M.H. and Chae K.S. (2008) A $60-\mathrm{Hz}$ sinusoidal magnetic field induces apoptosis of prostate cancer cells through reactive oxygen species. International Journal of Radiation Biology, 84, 945-955. https://doi.org/10.1080/09553000802460206

[167] Kranjc, S., Kranjc, M., Scancar J., Jelenc, J., Sersa, G. and Miklavcic, D. (2016) Electrochemotherapy by Pulsed Electromagnetic Field Treatment (PEMF) in Mouse Melanoma B16F10 in Vivo. Radiology and Oncology, 50, 39-48.

[168] Tatarov, I., Panda, A., Petkov, D., Kolappaswamy, K., Thompson, K., Kavirayani, A., et al. (2011) Effect of Magnetic Fields on Tumor Growth and Viability. Comparative Medicine, 61, 339-345.

[169] Tofani, S., Cintorino, M., Barone, D., Berardelli, M., De Santi, M., Ferrara, A., et al. (2002) Increased Mouse Survival, Tumor Growth Inhibition and Decreased Immunoreactive p53 after Exposure to Magnetic Fields. Bioelectromagnetics, 23, 230-238. https://doi.org/10.1002/bem.10010

[170] Tuffet, S., de Seze, R., Moreau, J.M. and Veyret, B. (1993) Effects of a Strong Pulsed Magnetic Field on the Proliferation of Tumour Cells in Vitro. Bioelectrochemistry and Bioenergetics, 30, 151-160. https://doi.org/10.1016/0302-4598(93)80073-4

[171] Verginadis, I., Karagounis, A., Simos, Y., Peschos, D., Karkabounas, S. and Evangelou, A. (2012) Beneficial Effects of Electromagnetic Radiation in Cancer. Electromagnetic Radiation. https://doi.org/10.5772/35456

[172] Wang, Z., Yang, P., Xu, H., Qian, A., Hu, L. and Shang, P. (2009) Inhibitory Effects of a Gradient Staticmagnetic Field on Normal Angiogenesis. Bioelectromagnetics, 30, 446-453. https://doi.org/10.1002/bem.20501

[173] Williams, C.D., Markov, M.S., Hardman, W.E. and Cameron, I.L. (2001) Therapeutic Electromagnetic Field Effects on Angiogenesis and Tumor Growth. Anticancer Research, 21, 3887-3891. 


\section{Appendix}

Appendix 1. Data bank for verification of the EM-coherency hypothesis for cancer.

1) Extremely low $50 \mathrm{~Hz}$ EMF field frequencies are located in a coherent frequency-zone that are able to inhibit and retard cancer

Many studies show that a $50 \mathrm{~Hz}$ electromagnetic wave at a nearly pure, transient-free $50 \mathrm{~Hz}$, is able to retard tumor and inhibit tumor formation (Hisamitsu, 1997; Wertheimer, 1979; Simkó, 1998; Pang, 2001; Tofani, 2002, 2003; Traitcheva, 2003; Morabito, 2010; Berg, 2010; Filipovic, 2014) or by using a 50 $\mathrm{Hz}$ wave with a typical modulation:

- Nucleosome-sized DNA fragmentation (a biochemical marker of apoptosis) was induced in human myelogenous leukemic cell lines, HL-60 and ML-1, when exposed to $50 \mathrm{~Hz}$ electromagnetic fields. This $50 \mathrm{~Hz}$ wave did not induce detectable DNA fragmentation in either human peripheral blood leukocytes or polymorphonuclear cells (Hisamitsu, 1997).

- Human colon adenocarcinoma and human breast adenocarcinoma exposed to $3 \mathrm{mT}$ static MF, modulated in amplitude with $3 \mathrm{mT}$ ELF-MF at $50 \mathrm{~Hz}$, showed morphological evidence of increased apoptosis (Tofani 2002).

- Anticancer activity of electromagnetic fields was observed by exposing mice bearing a subcutaneous human breast tumour to modulated MF extremely low frequency fields at $50 \mathrm{~Hz}$ at an intensity of $5.5 \mathrm{mT}$ (Tofani 2003).

- Increased apoptosis in human breast cancer cell lines occurred by exposure during 24 and $72 \mathrm{~h}$ to pulsed EMF ( $50 \mathrm{~Hz} ; 10 \mathrm{mT}$ ) compared with untreated control cancer cell lines (Filipovic, 2014).

\section{1) Extremely low non-coherent frequencies can promote cancer}

- Unipolar and bipolar PEMF fields of $5 \mathrm{mT}$ and PVMP fields of $0 \mathrm{mT}$ at frequencies of $15 \mathrm{~Hz}, 125 \mathrm{~Hz}$ and $625 \mathrm{~Hz}$ were tested on cancer cell lines derived from various types of tumors: CEM/C2 (acute lymphoblastic leukemia), SU-DHL-4 (B-cell lymphoma), COLO-320DM (colorectal adenocarcinoma), MDA-BM-468 (breast adenocarcinoma), and ZR-75-1 (ductal carcinoma). Cell morphology was observed, proliferation activity using WST assay was measured and simultaneous proportion of live, early apoptotic and dead cells was detected using flow cytometry. PEMF of $125 \mathrm{~Hz}$ and $625 \mathrm{~Hz}$ for $24 \mathrm{~h}-48$ $\mathrm{h}$ increased proliferation activity in the 2 types of cancer cell lines used, i.e. COLO-320DM and ZR-75-1. In contrast, any of employed methods did not confirm a significant inhibitory effect of hypothetic PVMP field on tumor cells (Loja T, 2014).

\section{2) Modulated $50 \mathrm{~Hz}$ and $60 \mathrm{~Hz} \mathrm{EM}$ frequencies can cause cancer}

Incoherent modulations (positioned in decoherent-zones) added to 50 and 60 $\mathrm{Hz}$ carrier waves can cause cancer.

- Power supply at 50 and $60 \mathrm{~Hz}$ contains a lot of harmonic distortion (Bulletin No. 8803PD9402, 1994; Schaffner, 2014). Due to this reason the chance on carcinogenesis and the risk of childhood leukemia increases at exposures of 
higher than $0.3 \mu \mathrm{T}$ according to: National Cancer Institute Electromagnetic fields and cancer, 2016; Ahlbom, 2000; Greenland, 2000; Kheifets, 2010.

- $50 \mathrm{~Hz}$ modulated with a sufficient high level of incoherent frequencies is able to cause cancer at a relatively low field strength. $50 \mathrm{~Hz}$ combined with a harmonic distortion of about 3\% can cause cancer in rats at field strength of $1000 \mu \mathrm{T}$ in mice after 800 days (Soff. 2016). But an estimated lower content of inharmonic distortions no cancer in animals (rats) at a strength of $500 \mu \mathrm{T}$ occurs after 2 years (of note: $50 \mathrm{~Hz}$ is positioned in a zone with a moderate coherence), (Yasui, 1997).

- $60 \mathrm{~Hz}$ with a sufficient amount of harmonic distortion can cause cancer at a field strength of $200 \mu \mathrm{T}$ in mice after 852 days at an amount of harmonic distortion less than 3\% (Boorman, 1999a). But a $60 \mathrm{~Hz}$ with a low amount of harmonic distortion did not cause cancer in animals at a high field strength of $1420 \mu \mathrm{T}$ in mice after 852 days (of note: $60 \mathrm{~Hz}$ is positioned near the border of low coherence), (McCormick et al., 1999).

- Both $50 \mathrm{~Hz}$ and $60 \mathrm{~Hz}$ combined with a cancer co-promoter agent can cause cancer at a relatively low field strength $20-200 \mu \mathrm{T}$ (Löscher and Mevissen et al. 1996, 1998, 2008; Cain, 1993; Stuchly, 1992; Beniashvili, 1991).

1.3) Extreme low frequencies located in coherent zones can inhibit and retard cancer

- Murine malignant tumour growth of mice inhibited, apoptosis of cancer cells induced, and arrest of neoangiogenesis was observed by a pulsed $0.16-1.34$ $\mathrm{Hz}$ treatment (Zhang X, 2002).

- Growth of S-180 sarcoma in mice was inhibited by a pulsed magnetic field at 0.8 T, $22 \mathrm{~ms}, 1 \mathrm{~Hz}$ (Chang et al., 1985).

- A pronounced decrease in tumor growth rate in animals exposed to a $5-\mathrm{Hz}$ interferential frequency for $1 \mathrm{hr}$ daily has been shown. (Ghannam, 2002).

- A significant decrease in the rate of tumor growth and increase in survival were observed for male and female mice exposed for $8 \mathrm{~h} /$ day to $100 \mathrm{mT}$, $0.8-\mathrm{Hz}$ square-wave from the onset of tumor until death or until the tumor volume reached a predetermined volume (Seze, 2000).

- A significant decrease in cell growth (56\%) of colon adenocarcinoma cells has been shown in cells exposed to $1 \mathrm{~Hz}$ or $25 \mathrm{~Hz}$ for 2 till $6 \mathrm{~h}$. at $1.5 \mathrm{mT}$ in the presence of dexamethasone (Ruiz-Gómez, 1999, 2002).

- The inhibition growth rate was significantly higher of murine osteosarcoma cells, treated with doxorubicin in the presence of $10 \times 10^{-3} \mathrm{mT}$ PEMF at 10 $\mathrm{Hz}$, compared to both non-exposed resistant cells and those non-treated with doxorubicin (Miyagi et al., 2000).

- Mice inoculated subcutaneously with B16-BL6 melanoma cells exposed to 25 $\mathrm{Hz}$ EMF for $3 \mathrm{~h}$ did not grow tumours after 38 days, however, the mice in the sham-field and reference controls showed massive tumours. Tumour growth was also affected by the intensity of the field, with mice exposed to a weak intensity field $(1-5 \mathrm{nT})$ forming smaller tumours than mice exposed to sham or stronger, high intensity $(2-5$ microT) fields $(\mathrm{Hu} \mathrm{JH}, 2010)$. 
- Exposure of mice injected with mouse breast cancer cells to electromagnetic fields, for $6 \mathrm{~h}$. daily at $100 \mathrm{mT}, 1-\mathrm{Hz}$, half-sine-wave unipolar magnetic fields for as long as $4 \mathrm{wk}$, suppressed tumor growth (Tatarov, 2011).

- Rat liver cancer exposed to $0.9 \mathrm{~Hz}$ and $3.0 \mathrm{~Hz}$ magnetic fields at 13 - 42 Gauss and 0.6 Tesla showed apoptosis, necrosis and inflammatory infiltration of the malignant carcinoma (Emara, 2013).

- Electromagnetic exposure by $0.4 \mathrm{~T}, 7.5 \mathrm{~Hz}$ for 43 days inhibited the growth and metastasis of melanoma cancer cells and improved immune function of tumor-bearing mice (Nie Y., 2013).

- Microarray of human A549 lung adenocarcinoma cells exposed for 1 hour to $8 \mathrm{~Hz}$ electromagnetic wave showed a duration-dependent inhibitory effect and the cell cycle and apoptosis-related genes had 2-fold upregulation and 40 genes had 2-fold downregulation (Feng, 2013).

- Pulsed EMF at $20 \mathrm{~Hz}$ and intensity of $3 \mathrm{mT}$ during 3 days showed cytotoxic to breast cancer cells (Crocetti, 2013).

- The effect of the A3AR agonist in tumor cells was enhanced in the presence of pulsed EMFs and blocked by using a well-known selective antagonist. The results demonstrated that pulsed EMF exposure significantly increased the anti-tumor effect modulated by A3ARs at a pulse duration of $1.3 \mathrm{~ms}(1300$ $\mathrm{Hz}$ ) and frequency of $75 \mathrm{~Hz}$ (Vincenzi, 2012).

- Human hematoma cell line cells decreased with a variety of Xray irradiation doses combined to $100 \mathrm{~Hz}$ EMF at $0.7 \mathrm{mT}$ and cause accumulation of apoptotic effects in BEL-7402 cells (Jian et al., 2009).

- Five periods of combined $100 \mathrm{~Hz}$ MFs and 4 Gy X-ray could significantly extend the overall days of survival and reduce the tumor size compared to MF or X-ray alone. A greater number of $100 \mathrm{~Hz}$ MF exposure periods could further improve the survival and inhibit tumor growth in hepatoma-implanted mice when combined with 4 Gy X-ray (Wen, 2011).

- Exposure of breast tumors to a $120 \mathrm{~Hz}$ magnetic field 10 minutes per day with $0,10 \mathrm{mT}, 15 \mathrm{mT}$ or $20 \mathrm{mT}$ significantly reduced tumor growth, reduced the percentage of area stained for $\mathrm{CD} 31$ indicating a reduction in the extent of vascularization and there was a concomitant increase in the extent of tumor necrosis (Williams, 2001).

- Male Fischer-344 rats subjected to the modified resistant hepatocyte model and exposed to $4.5 \mathrm{mT}-120 \mathrm{~Hz}$ ELF-EMF inhibited preneoplastic lesions chemically induced in the rat liver through the reduction of cell proliferation, without altering the apoptosis process (Jiménez-García, 2010).

- Exposure to $20 \mathrm{mT}$ for 10 minutes $120 \mathrm{~Hz}$ semi sine wave pulse signal of variable intensity of murine 16/C mammary adenocarcinoma tumor fragments reduced the vascular volume fraction and increased the necrotic volume of the tumor (Cameron, 2005, 2014).

1.4) Effects of extremely low frequencies located in coherent zones and cancer cells

- Glioblastoma Multiforme (GBM) cell line (U87), in vitro, were exposed to 
various ELF-PEMFs continuous square waves with 10,50 or $100 \mathrm{~Hz}$ frequencies and 50 or $100 \mathrm{G}$ amplitudes. The data suggest that the proliferation and apoptosis of human GBM are influenced by exposure to ELF-PEMFs in different time-dependent frequencies and amplitudes (Akbarnejad, 2016) (of note: square waves can have typical influences).

1.5) Combinations of extreme low frequencies located in coherent zones can inhibit and retard cancer

- Modulated $0.5 \mathrm{~Hz}$ and $16.5 \mathrm{~Hz}$ produced a pronounced antitumor effect and inhibited or suppressed the growth of Ehrlich ascites carcinoma (EAC) in mice. The maximum effects occured at 100 and $300 \mathrm{nT}$ at a frequency of 4.4 Hz. The necrosis was prevailing type of cell death (Novikov, 2005, 2009).

- A low-intensity frequency-modulated (25 - $6 \mathrm{~Hz})$ EMF pattern daily, $1 \mathrm{~h}$, exposures inhibited the growth of malignant cell lines, and HeLa cells but did not but did not affect the growth of non-malignant cells (Buckner, 2015).

1.6) Mhz and GHz EM frequencies located in coherent zones can inhibit and retard cancer

- Pulsed electric fields of of $0.5 \mathrm{~Hz}$ and greater than $20 \mathrm{kV} / \mathrm{cm}$, with rise times of $30 \mathrm{~ns}$ and durations of $300 \mathrm{~ns}(3.32 \mathrm{MHz})$ penetrate into the interior of tumor cells and cause tumor cell nuclei to rapidly shrink and tumor blood flow to stop. Melanomas shrink by $90 \%$ within two weeks. A second treatment at this time can result in complete remission (2006).

- Modulated RF field of $900 \mathrm{MHz}$ with a 8:1 pulsed signaling system at a SAR of $1 \mathrm{~W} / \mathrm{kg}$ induced anti-proliferative activity in human neuroblastoma SH-SY5Y cells, also the appearance of the sub-G1 peak, a hallmark of apoptosis, was highlighted after a 24-h exposure, together with a significant decrease in mRNA levels of Bcl-2 and survivin genes, both interfering with signaling between G2-M arrest and apoptosis (Buttiglione, 2007).

- A study of ablation efficiencies revealed that $18-\mathrm{GHz}$ microwave results in the largest difference in the temperature rise between cancer and normal tissues as well as the highest ablation efficiency, reaching 20 times that of 2 $\mathrm{GHz}$. Thermal profile study on the composite region of cancer and fat also showed significantly reduced collateral damage using $18 \mathrm{GHz}$. Application of low-power ( $1 \mathrm{~W}$ ) 18-GHz microwave on the nude mice xenografted with human breast cancer cells resulted in recurrence-free treatment. The proposed microwave ablation method can be a very effective process to treat small-sized tumor with minimized invasiveness and collateral damages (Yoon, 2011).

- Coherent monochromatic frequency signals at $\mathrm{GHz}$ are able to suppress tumor growth (Radzievsky, 2004; Beneduci, 2005). The biological effects produced by low power millimeter waves (MMW) were studied on the RPMI 7932 human melanoma cell line. Three different frequency-type irradiation modes were used: the 53.57 - $78.33 \mathrm{GHz}$ wide-band frequency range, the $51.05 \mathrm{GHz}$ and the $65.00 \mathrm{GHz}$ monochromatic frequencies. In all three irradiation conditions, the radiation energy was low enough not to increase the 
temperature of the cellular samples. The wide-band irradiation treatment effectively inhibited cell growth, while both the monochromatic irradiation treatments did not affect the growth trend of RPMI 7932 cells (Beneduci, 2005).

- A coherent pulsed electromagnetic field at a coherent $\mathrm{MHz}$ frequency is able to reduce cancer in a cell lines (Agulan, 2015).

- Electric pulses $20 \mathrm{~ns}$ or less kill a wide variety of human cancer cells in vitro, induce tumor regression in vivo: a total of 200 pulses of 20 ns duration at 25 $\mathrm{kV} / \mathrm{cm}$ led to an $84 \%$ decrease in viable cells compared to controls. A total of 200 pulses of $20 \mathrm{~ns}$ duration at $35 \mathrm{kV} / \mathrm{cm}$ caused complete eradication of the cells (Garon, 2007).

- Nanosecond pulsed electric fields (nsPEFs) can affect the intracellular structures of cells in vitro. This study shows the direct effects of nsPEFs on tumor growth, tumor volume, and histological characteristics of normal skin and B16-F10 melanoma in SKH-1 mice. A melanoma model was set up by injecting B16-F10 into female SKH-1 mice. After a 100-pulse treatment with an $\mathrm{nsPEF}$ (40-kV/cm field strength; 300-ns duration; $30-\mathrm{ns}$ rise time; $2-\mathrm{Hz}$ repetition rate), tumor growth and histology were studied.After nsPEF treatment, tumor development was inhibited with decreased volumes post-nsPEF treatment compared with control tumors $(\mathrm{P}<0.05)$ (Chen XR, 2009).

- Noninvasive electroporation was performed by magnetic field pulse generator connected to an applicator consisting of round coil. Subcutaneous mouse B16F10 melanoma tumors were treated with intravenously injection of cisplatin, PEMF (480 bipolar pulses, at frequency of $80 \mathrm{~Hz}$, pulse duration of $340 \mu \mathrm{s}$ ) or with the combination of both therapies (electrochemotherapyPEMF + CDDP) (Kranjc, 2016).

- Tumors in treated mice showed nsPEF-mediated nuclear condensation $(3 \mathrm{~h}$ post-pulse), cell shrinkage $(1 \mathrm{~h})$, increases in active executioner caspases and terminal deoxynucleotidyl transferase dUTP nickend-labeling $(1 \mathrm{~h})$ with decreases in vascular endothelial growth factor expression (7d) and $\mathrm{mi}$ cro-vessel density (14 d). Tumors disappeared with $100 \mathrm{~ns}$ pulses to nearly non-detectable levels 14 - 21 days after the first treatment in 6 of 8 mice. Optimal treatments included $76.5 \%$ tumor-free survival for nearly 9 months (Chen X, 2012).

- Nanosecond pulse electric fields (nsPEFs) ablate melanoma by induction of apoptosis and inhibition of angiogenesis. Four hepatocellular carcinoma cell lines HepG2, SMMC7721, Hep1-6, and HCCLM3 were pulsed to test the anti-proliferation and anti-migration ability of $100 \mathrm{~ns}$ nsPEFs in vitro. The animal model of human subdermal xenograft HCCLM3 cells into BALB/c nude mouse was used to test the anti-tumor growth and macrophage infiltration in vivo (Chen $\mathrm{X} 2014)$.

- NsPEF could not only induce cell apoptosis via dependent-mitochondria intrinsic apoptosis pathway, but also inhibit cell proliferation through repressing NF- $\mathrm{BB}$ signaling pathway to reduce expressions of cyclin proteins. 
$\mathrm{NsPEF}$, at $100 \mathrm{~ns}$ pulses $(10 \mathrm{MHz})$ in duration and $20 \mathrm{kV} / \mathrm{cm}$ in intensity applied at a frequency of $0.5 \mathrm{~Hz}$, could inactivate metastasis and invasion in cancer cells by suppressing $\mathrm{Wnt} / \beta$-Catenin signaling pathway to down-regulating expressions of VEGF and MMPs family proteins. It is found that nsPEF induce tumor cell apoptosis, destroy tumor microenvironment, and depress angiogenesis in tumor tissue in vivo (Ren Z, 2015).

1.7) $\mathrm{Mhz}$ and $\mathrm{GHz}$ modulated with ELF frequencies located in coherent zones can inhibit and retard cancer

- Apoptosis of human ovarian carcinoma cell Line (SKOV3) induced by the nanosecond pulsed electric field $(10 \mathrm{kV} / \mathrm{cm}, 100 \mathrm{~ns}, 1 \mathrm{~Hz})$ effects on intracellular calcium concentration $\left(\mathrm{Ca}^{2+}\right)$. The results showed that the early apoptosis rate of the treatment group was significantly higher than that of the control group. Since nsPEF can penetrate cell membrane due to its high frequency components, one of the mechanisms of nsPEF-induced apoptosis may be that activating intracellular calcium stores can increase the $\left[\mathrm{Ca}^{2+}\right] \mathrm{i}$, and consequently, the apoptotic signal pathway can be induced (Yao, 2008).

- To determine if nanosecond pulsed electric fields (nsPEFs) is equally effective in treatment of human breast cancer, 30 human breast cancer tumors across $30 \mathrm{Balb} / \mathrm{c}(\mathrm{nu} / \mathrm{nu})$ mice were exposed to 720 pulses of $100 \mathrm{~ns}(7.2 \mathrm{GHz})$ duration, at 4 pulses per second and $30 \mathrm{kV} / \mathrm{cm}$. Two weeks after treatment, the growth of treated tumors was inhibited by $79 \%$. Pulsed tumors exhibited apoptosis evaluated by TUNEL staining, inhibition in Bcl-2 expression and decreased blood vessel density. Notably, CD34, vascular endothelial growth factor (VEGF) and VEGF receptor (VEGFR) expression in treated tumors were strongly suppressed. The results suggest nsPEFs is able to inhibit human breast cancer development and suppress tumor blood vessel growth, indicating nsPEFs may serve as a novel therapy for breast cancer in the future (Wu S., 2013).

- Exposing the tumor tissue female Balb/c mice to $10 \mathrm{MHz}$ modulated $4.5 \mathrm{~Hz}$, 2 Gauss square wave magnetic field for 2 weeks at a rate 2 hours/day inhibited tumor growth and increased the survival period of the animals. However, group B showed more improvements than did group C that was attributed to some distortions in the square waveform. The use of typical ELF EMF at $0.5 \mathrm{~Hz}$ and $0.7 \mathrm{~Hz}$ electric field exposed to Balb/c mice g carrying Ehrlich tumor proved that tumor cells can be controlled and recovery of rgans such as liver and spleen are possible (Fadel, 2011, 2015).

1.8) $\mathrm{Mhz}$ and $\mathrm{GHz}$ frequencies located in decoherent-zones may cause cancer

- Human cells exposed to continuous $830 \mathrm{MHz}$ electromagnetic fields at 2.6 $8.8 \mathrm{~W} / \mathrm{kg}$ at a nonthermal level can lead to acquire premalignant genotypes associated with elevated levels of aneuploidy and abnormalities in replication mode as expressed in asynchrony in the replication timing of homologous chromosomal regions associated with chromosome segregation. These findings support the view that exposure to this kind of RF radiation of average 
SAR values of $2.6-8.8 \mathrm{~W} / \mathrm{kg}$ can lead to a genotoxic effect of the electromagnetic radiation and may lead to a carcinogenic activity through a non thermal pathway (Mashevich, 2003).

- Male rats of wistar strain exposed to modulated $2.45 \mathrm{GHz}$, at an absorption rate (SAR) of $0.11 \mathrm{~W} / \mathrm{Kg}$, showed a significant increase in comet head, tail length and in tail movement in exposed brain cells. An analysis of antioxidant enzymes glutathione peroxidase and superoxide dismutase showed a decrease while an increase in catalase was observed. The study concludes that the chronic exposure to these radiations may cause significant damage to brain, which may be an indication of possible tumour promotion (Kesari, 2010).

- Changes in the overall pattern of protein phosphorylation suggest that incoherent modulated $900 \mathrm{MHz}$ activated a variety of cellular signal transduction pathways, among them the hsp27/p38MAPK stress response pathway. Based on the known functions of hsp27, a hypothesis has been put forward that this kind of electromagnetic fields induced activation of hsp27 may facilitate the development of brain cancer by inhibiting the cytochrome c/caspase-3 apoptotic pathway (Leszczynski 2002).

- Exposure of rats by a combination of a continuous wave form in a nearby coherent zone at a low exposure level does not affect tumor growth. Low-level exposure of mammary-tumor-prone mice to $2450 \mathrm{MHz}$ RFR circularly polarized waveguides (CWG) for 18 months ( $20 \mathrm{~h} /$ day, 7 days/wk) to continuous-wave $2450 \mathrm{MHz}$ RFR at a whole body average specific absorption rate (SAR) of $0.3 \mathrm{~W} / \mathrm{kg}$ did not affect mammary tumor incidence, latency to tumor onset, tumor growth rate, or animal longevity when compared with sham-irradiated controls (Frei, 1998).

1.9) $\mathrm{Mhz}, \mathrm{GHz}, \mathrm{THz}$ frequencies located in decoherent zones can cause cancer (table 2b)

- Low-level laser therapy (LLLT) at $660 \mathrm{~nm}$ induced significantly the proliferation of a squamous carcinoma cell line SCC25 cells at $1.0 \mathrm{~J} / \mathrm{cm}^{2}$, which was accomplished by an increase in the expression of cyclin D1 and nuclear $\beta$-catenin. The results of this study demonstrated that LLLT exerts a stimulatory effect on proliferation and invasion of SCC25 cells, which was associated with alterations on expression of proteins studied (Gomes Henriques, 2014).

- Laser irradiation three times once a day during three days with a $660 \mathrm{~nm} 50$ $\mathrm{mW}$ CW laser, beam spot size $2 \mathrm{~mm}^{2}$, irradiance $2.5 \mathrm{~W} / \mathrm{cm}^{2}$ and irradiation times of $60 \mathrm{~s}\left(\right.$ dose $\left.150 \mathrm{~J} / \mathrm{cm}^{2}\right)$ and $420 \mathrm{~s}\left(\right.$ dose $1050 \mathrm{~J} / \mathrm{cm}^{2}$ ) respectively on B16F10 melanoma cells in a vitro study increased in the hypodiploid melanoma cells at $72 \mathrm{~h}$ post-irradiation, and at $1050 \mathrm{~J} / \mathrm{cm}^{2}$ in the vivo experiment (Frigo, 2009).

- Low level laser irradiation at $660 \mathrm{~nm}$ or $780 \mathrm{~nm}$ at $6.15 \mathrm{~J} / \mathrm{cm}^{2}$ can modify oral dysplastic cells (DOK) and oral cancer cells (SCC9 and SCC25) growth by modulating signalling pathways; LLLT significantly modified the expression of proteins related to progression and invasion in all the cell lines, and could 
aggravate oral cancer cellular behaviour, increasing the expression of different proteins and producing an aggressive Hsp90 isoform (Sperandio, 2013).

- High frequency coherent signals of $900 \mathrm{MHz}$ electromagnetic fields modulated with coherent extreme low frequencies do not cause cancer at a specific absorption rate (SAR) value of $0.4 \mathrm{~W} / \mathrm{kg}$ in genetically predisposed species after about 1 year exposure (Sommer, 2004).

- The mutagenic effect on Escherichia coli strains of UV radiation emitted by a XeCI laser (lambda $=308 \mathrm{~nm}$, tau $=20 \mathrm{~ns}, 100 \mathrm{~mJ}$ pulse energy) has been analyzed as a function of the exposure dose and compared with the effect induced by $254 \mathrm{~nm}$ radiation emitted by a conventional germicidal lamp. Mutations can involve any genome site and therefore can give rise to various phenotypes, which then can be suitably selected. As a consequence, the impact of the induced mutagenesis is outstanding, both in scientific and industrial fields. In particular suitable doses of UV radiation can induce mutations, while higher doses can cause cell death, due to the induction of manifold damages to DNA (Belloni, 2005).

- The action spectrum (sensitivity per incident photon as a function of wavelength) for melanoma induction shows appreciable sensitivity at 365, 405, and probably $436 \mathrm{~nm}$, as shown in heavily pigmented backcross hybrids of the genus Xiphophorus (platyfish and swordtails) that are very sensitive to melanoma induction by single exposures to UV, (Setlow 1993).

- The action spectrum of SSC (squamous cell carcinoma) has been determined experimentally in hairless mice; this action spectrum shows a peak at $293 \mathrm{~nm}$ in the UV-B range (De Gruijl et al., 1993).

1.10) $\mathrm{Mhz}$ and $\mathrm{GHz}$ frequencies located in coherent zones with estimated modulations in non-coherent zones can cause cancer

- A high frequency $900 \mathrm{MHz}$ signal located in a coherent zone at a low SAR of $0.13-1.4 \mathrm{~W} / \mathrm{kg}$, modulated with estimated incoherent frequencies in the decoherent soliton frequency-zone, can cause cancer after 2 years exposure in animals (Repacholi, 1997).

- A high frequency signal at a high SAR of at least $5.0 \mathrm{~W} / \mathrm{kg}$ caused DNA damage (strand breaks/alkali labile sites) in leukocytes using the alkaline $(\mathrm{pH}>13)$ single cell gel electrophoresis (SCG) assay in vitro studies of modulated 837 and $1909.8 \mathrm{MHz}$ exposed human blood leukocytes and lymphocytes. This demonstrates that, this kind of EMF is capable of inducing chromosomal damage in human lymphocytes (Tice, 2002).

- High frequency signals of 900 and $1900 \mathrm{MHz}$ located in a coherent zone, and modulated with estimated incoherent frequencies in the decoherent soliton frequency-zone at a high SAR of $6 \mathrm{~W} / \mathrm{kg}$ during an exposure of 2 years can show schwannomas in the heart of male rats (Wyde et al., 2016).

1.11) Mhz and GHz EM frequencies located in decoherent zones with estimated modulations in non-coherent zones can cause cancer at a lower exposure level

- Expose mice to modulated $9270 \mathrm{MHz}$ waves can causes cancer (Prausnitz 
and Susskind, 1962). Rat exposed to pulsed $2450 \mathrm{MHz}$ at $0.48 \mathrm{~mW} / \mathrm{cm}^{2}$ and at SARs up to $0.4 \mathrm{~W} / \mathrm{Kg}, 21.5 \mathrm{hr} /$ day, 7 days/wk, 25 month show that carcinomas are increased and malignant tumors of endocrine and exocrine organs as a group are increased (Guy et al. 1983, 1985).

- Modulated/pulsed exposure of rats 2450-MHz EMF 21.5 h/day, for 25 months at an average specific absorption rate (SAR) of $0.4 \mathrm{~W} / \mathrm{kg}$ provide an increase of malignancies (Chou CK 1992).

- Mice exposed to modulated $1.966 \mathrm{GHz}$ fields with intensities of $4.8 \mathrm{~W} / \mathrm{m}$ (2) during 24 months displayed an enhanced lung tumour rate and an increased incidence of lung carcinomas as compared to the controls (Tillmann, 2010).

- A replication of the Tillmann study of exposed mice has been performed using higher numbers of animals per group exposed to modulated $1.966 \mathrm{GHz}$ exposed at low to moderate exposure levels (0.04 and $0.4 \mathrm{~W} / \mathrm{kg} \mathrm{SAR})$. It has been confirmed that numbers of tumors of the lungs and livers in exposed animals were significantly higher than in sham-exposed controls. In addition, lymphomas were also found to be significantly elevated by exposure (Lerchl, 2015).

1.12) $\mathrm{Mhz}$ and $\mathrm{GHz}$ frequencies located in non-coherent zones with a co-carcinogen can cause cancer

- Mice exposed to microwave irradiations irradiated with athermal (5 $\left.\mathrm{mW} / \mathrm{cm}^{2}\right)$ or subthermal $\left(15 \mathrm{~mW} / \mathrm{cm}^{2}\right)$ doses of $2450 \mathrm{MHz}$ microwaves during 6 months resulted in a significant acceleration of the development of benzopyrene-induced skin cancer and in shortening of life span of the tumour-bearing hosts. This effect seemed to be dose-dependent since subthermal doses $\left(15 \mathrm{mV} / \mathrm{cm}^{2}\right)$ and longer (3 months) expositions to microwaves were more efficient as compared to athermal doses $\left(5 \mathrm{~mW} / \mathrm{cm}^{2}\right)$ and shorter preirradiations (Szudziński, 1982).

- Mice irradiated by nonthermal (1 or $\left.10 \mathrm{~mW} / \mathrm{cm}^{2}\right)$ or thermogenic $(40$ $\mathrm{mW} / \mathrm{cm}^{2}$ ) 2450-MHz microwave (MW) fields showed a significant enhancement of the teratogenic potency of ara-C after combined exposure to both ara-C and microwave exposure during pregnancy. The possibility that specific cellular interactions of MW/RFs are connected with the pulse modulation of the carrier wave is considered (Marcickiewicz, 1986).

- Long-term exposure of mice to 2450-MHz MWs resulted in acceleration of the appearance and growth of tumors initiated by three different carcinogens, and a higher risk of cancer development in mice exposed to subcarcinogenic doses of initiators. Microwave-exposed C3H/HeA mice developed breast tumors earlier than controls (322 days in controls, 261 days for $5 \mathrm{~mW} / \mathrm{cm}^{2}$ and 219 days for $15 \mathrm{~mW} / \mathrm{cm}^{2}$ ). A similar acceleration was observed in the development of BP-induced skin cancer in mice (Szmigielski, 1982).

1.13) $\mathrm{THz}$ and light frequencies located in coherent zones may and can inhibit and retard cancer

- Treatment of human breast cancer (MCF7) cancer cells is achieved at the exposure of $3600 \mathrm{~nm}$ (Peidaee, 2013). 
- Glioblastoma cell cultures cell line A-172 irradiated laser at a wavelength of $808 \mathrm{~nm}$ at 18, 36 and $54 \mathrm{~J} / \mathrm{cm}(2)$ suppressed proliferation of A-172 cells in a fluence-dependent manner (Murayama, 2012).

- The near-infrared $808 \mathrm{~nm}$ low-power laser irradiation (LLI) potentially suppressed the cell proliferation of human derived glioblastoma (A-172) (Fukuzaki, 2014).

- A diode $808 \mathrm{~nm}$ GaAlAs continuous wave laser has an inhibitory effect on the proliferation of human hepatoma cells line HepG2 and J-5. The mechanism of inhibition might be due to down-regulation of synemin expression and alteration of cytokeratin organization that was caused by laser irradiation (Liu YH, 2004).

- THz-pulses induced increases in the levels of multiple cell cycle regulatory and tumor suppressor proteins, favorable changes in the expression of multiple genes suggesting that cellular DNA repair machinery is activated in response to THz-pulse-induced DNA damage (Titova, 2013).

- Based on mesoscopic modelling of DNA breathing dynamics in a $\mathrm{THz}$ field, it has been suggested that $\mathrm{THz}$ radiation may amplify existing (or create new) open states in the double helix, thereby affecting transcription initiation or binding of transcription factors and influences of terahertz radiation effect on gene expression in mouse mesenchymal stem cells (Alexandrov, 2010, 2013).

Appendix 2. Databank for reported EM frequencies of the analyzed biological studies.

Author, year $(\mathrm{x}, \mathrm{y}, \mathrm{z})$ : Author name, year of published biological experiment (applied biological frequency: $x$; first nearby calculated algorithmic frequency: $y$, percentual difference between applied frequency and nearby calculated frequency: $z \%)$.

1) Cases of frequencies in coherent soliton frequency bands able to inhibit and retard cancer* (see below)

1) Raylman et al., 1996 (7T uniform static magnetic field)

2) Zhang X. et al. 2002, pulsed $(0.16 \mathrm{~Hz} ; 0.16 ; 0.0 \%)$

3) Nuccitelli et al. 2006, 3.33 MHz pulsed (3.33 MHz, 3.316, 0.51\%); (0.5 Hz; 0.5; 0.0\%)

4) Fadel 2015 (modulated $0.5 \mathrm{~Hz} ; 0.5 ; 0.00 \%) ;(0.7 \mathrm{~Hz}, 0.715,2.1 \%)$

5) Yin S. 2014, pulsed (10 MHz, 9.93, 0.71\%); (0.5 Hz; 0.5; 0.00\%)

6) Emara et al. $2013(0.9 \mathrm{~Hz} ; 0.89 ; 1.1 \%)$

7) Tuffet et al. $1993(0.8 \mathrm{~Hz} ; 0.79 ; 1.27 \%)$

8) Seze et al. $2000(0.8 \mathrm{~Hz} ; 0.79 ; 1.27 \%)$

9) Novikov 2005, 2009 combinations frequencies (1 Hz; $4.4 \mathrm{~Hz} ; 16.5 \mathrm{~Hz} ; 1.5 \%)$

10) Tatarov et al. $2011(1 \mathrm{~Hz} ; 1.0 ; 0.0 \%)$

11) Chang et al. $1985(1.0 \mathrm{~Hz} ; 1.0 ; 0 \%)$

12) Ruiz-Gómez 1999, $2002(1 \mathrm{~Hz} ; 1.0 ; 0.0 \%)$

13) Zhang X. et al, 2002 (1.34 Hz; stab. 1.33; 0.60\%)

14) Emara et al. 2013 ( $3 \mathrm{~Hz} ; 3 ; 0.0 \%)$

15) Wu S. 2013 (4 Hz, 4.0; 0.0\%)

16) Fadel 2010, 2011 modulated (4.5 Hz; 4.500; 0.00\%); (10 MHz, 9.93, 0.71\%)

17) Smith 1986 (4.5 Hz; $4.5 \mathrm{~Hz}$; 0\%) 


\section{Continued}

18) Ghannam $2002(5 \mathrm{~Hz} ; 5.06 ; 1.2 \%)$

19) Buckner 2015 combinations of ( $6 \mathrm{~Hz}, 6 \mathrm{~Hz}, 0 \%)$; $(25 \mathrm{~Hz}, 24.58 ; 1.7 \%)$

20) Nie Y. 2013 (7.5 Hz; stab freq. 7.59; 1.2\%)

21) Feng 2013 (8Hz; 8; 0\%)

22) Miyagi $2000(10 \mathrm{~Hz} ; 10.1 ; 1.0 \%)$

23) Bellossi pulsed 1991 (12 Hz; 12; $0 \%)$

24) Crocetti 2013 (20 Hz, stab.20.24; 1.2\%)

25) Ruiz-Gómez ( $25 \mathrm{~Hz} ; 25.28$; 1.11\%)

26) Yamaguchi et al. $2006(25 \mathrm{~Hz}, 25.3 ; 1.11 \%)$

27) Hu et al. 2010 (25 Hz; $25.3 \mathrm{~Hz} ; 1.11 \%)$

28) Rannung 1993 ( $50 \mathrm{~Hz}, 50.56$; 1.11\%)

29) Hisamitsu et al. 1997 (50 Hz; 50.56; 1.11\%)

30) Simkó et al. 1998 (50 Hz; 50.56; 1.11\%)

31) Pang 2001 ( $50 \mathrm{~Hz} ; 50.56 ; 1.11 \%)$

32) Tofani et al. 2002, 2003 (50 Hz; 50.56; 1.11\%)

33) Traitcheva 2003 ( $50 \mathrm{~Hz} ; 50.56 ; 1.11 \%)$

34) Santini et al. $2005(50 \mathrm{~Hz} ; 50.56 ; 1.11 \%)$

35) Morabito et al. 2010 (50 Hz; 50.56; 1.11\%)

36) Berg 2010 (50.00; 50.56; 1.11\%)

37) Filipovic 2014, pulsed ( $50 \mathrm{H} ; 50.56 ; 1.11 \%$ )

38a) Chen YC. 2010 (60; stab. 60.75; 1.24\%)

38b) Koh EK, 2008 (60; stab. 60.75; 1.24\%)

39) Vincenzi 2012 (75 Hz; 75.8, 1.1\%)

40) Jian et al. 2009 (100 Hz; 101.1; 1.1\%)

41) Wen et al. $2011(100 \mathrm{~Hz} ; 101.1 ; 1.1 \%)$

42) Williams $2001(120 \mathrm{~Hz} ; 121.5 ; 1.2 \%)$

43) Jiménez-García 2010 (120 Hz; 121.5; 1.2\%)

44) Cameron et al. $2014(120 \mathrm{~Hz} ; 121.5 ; 1.2 \%)$

45) Omote $1990(200 \mathrm{~Hz} ; 202.2 ; 1.1 \%)$

46) Bellosi 1991 (460 Hz; 455.1; 1.1\%)

47a) Vincenzi $2012(1300 \mathrm{~Hz} ; 1296,0.31 \%)$

47b) Kranjc $2016(2.941 \mathrm{KHz}, 2.8961 \mathrm{KHz}, 1.54 \%) ;(80 \mathrm{~Hz}, 81 \mathrm{~Hz}, 1.23 \%)$

48) Agulan 2015 (pulsed 3.3 MHz; 3.32; 0.49\%); (656, 648; 1.24\%)

49) Ren Z. 2015 (10 MHz; 9.93, 0.71\%; $0.5 \mathrm{~Hz} ; 0.5 ; 0.00 \%)$

50) Wang J. 2012 (10 MHz; $9.93 \mathrm{MHz} ; 0.71 \%)(0.5 \mathrm{~Hz}, 0.5 \mathrm{~Hz} ; 0.0 \%)$

51) Chen X. 2012, 2014 (10 MHz, $9.93 \mathrm{MHz}$; 0.71\%); (33.3 MHz, $33.5 \mathrm{MHz}$; 0.63\%); (0.5 Hz, $0.5 \mathrm{~Hz}$; $0.0 \%) ;(1.0 \mathrm{~Hz}, 1.0 \mathrm{~Hz} ; 0.0 \%)$

51b) Chen XR 2009 (300-ns: $3.33 \mathrm{MHz} ; 3.314 \mathrm{MHz}, 0.48 \%$ ) ; $2 \mathrm{~Hz} ; 2$; 0\%)

52) Yao 2008 pulsed ( $10 \mathrm{MHz} ; 9.93,0.71 \% ; 1 \mathrm{~Hz} ; 1.0 ; 0.0 \%)$

53) Garon 2007 (50 MHz; 50.34; 0.68\%)

54) Buttiglione 2007 (modulated $900 \mathrm{MHz} ; 905.9 ; 0.66 \%$ )

55) Wu S. 2013 (7.2 GHz; 7.247; 0.65\%)

56) Yoon 2011 (18 GHz; 18.08; 0.44\%)

57) Beneduci 2005 (46.00 GHz; 45.79; 0.46\%)

58) Beneduci 2005 (51.05 GHz; 51.54; 0.95\%)

69) Radzievsky 2004 (61.22 GHz; stab. 61.09; 0.2\%)

60) Beneduci 2005 (65.00 GHz; 65.23; 0.35\%)

61) Liu YH 2004 (808 nm; stab. freq. 799.0; 1.1\%)

62) Murayama 2012 (808 nm; stab. freq. $799.0 ; 1.1 \%)$

63) Fukuzaki 2014 (808 nm; 799.0, 1.13\%)

64) Peidaee 2013 (3600 nm; 3598.4; 0.04\%)

65) Peidaee 2013 (3800 nm; 3598.4; 0.34\%)

2) Cases of non-coherent EM frequency bands that may initiate and/or promote cancer

66) Mashevich 2003 (830 MHz; stab. 848.96; 2.23\%)

67) Leszczynski 2002 (modulated 900 MHZ, stab. 905.9; >0.66\%)

68) Kesari 2010 (2.45 GHz; stab. 2.42; 1.43\%)

69) Beniashvili 1991 (cocarcinogen and $50 \mathrm{~Hz}$, stab. 50.56; 1.11\%) 


\section{Continued}

70) Löscher Mevissen et al. 1996, 1999 (cocarcinogen and $50 \mathrm{~Hz}$, stab. 50.56; 1.11\%)

71) Ahlbom 2000 (50 and $60 \mathrm{~Hz}$; >1.25\%)

72) Greenland 2000 (50 and $60 \mathrm{~Hz} ;>1.25 \%)$

73) Kheifets 2010 ( 50 and $60 \mathrm{~Hz}$; >1.25\%)

74) National Cancer Institute Electromagnetic fields and cancer, 2016 (50 and $60 \mathrm{~Hz} ;>1.25 \%$ )

75) Soffritti 2016 (50.00 Hz combined with harmonic distortions 3\%; stab. 50.56; >1.11\%)

76) Soffritti 2016 (cocarcinogen and modulated $50.00 \mathrm{~Hz}$; stab. 50.56; 1.11\%)

77) Stuchly 1992 (cocarcinogen and $60 \mathrm{~Hz}, 60.75 ; 1.24 \%$ )

78) Cain 1993 (cocarcinogen and $60 \mathrm{~Hz}, 60.75 ; 1.24 \%$ )

79) Loja 2014 (125 Hz, 128; 2.3\%)

80) Loja 2014 (625 Hz, 606.2; 3.1\%)

81) Repacholi 1997 (modulated $900 \mathrm{MHz}$, stab. 905.9; >0.66\%)

82) Wyde ME 2016 (modulated 900, stab. 905.9, >0.66\%)

83) Wyde ME 2016 (modulated $1900 \mathrm{MHz}$, stab.1909.1;>0.48\%)

84) Tillmann et al. 2010 (modulated $1.97 \mathrm{GHz}$; stab. 1.909; >3.20\%)

85) Lerchl 2014 (modulated $1.97 \mathrm{GHz}$; stab. freq. 1.909; >3.20\%)

86) Roszkowski 1980b (2.45 GHz; stab. 2.42; 1.43\%)

87) Szudzinski 1982 (cocarcinogenic $2.45 \mathrm{GHz}$; stab. 2.42; 1.43\%)

88) Guy 1985 (modulated 2.45 GHz; stab. 2.42; >1.43\%)

89) Marcickiewicz 1986 (2,45 GHz, stab. 2.42; 1.43\%)

90) Szmigielski 1982 (cocarcinogen and $2.45 \mathrm{GHz}$, stab. 2.42; 1.43\%)

91) Balcer-Kubiczek 1989 (cocarcinogen $2.45 \mathrm{GHz}$, stab. 2.42; 1.43\%)

92) Chou CK 1992 (modulated 2.45 GHz; stab. 2.42; 1.43\%)

93) Johnson EH, 1999 (2.45 GHz; stab. 2.42; 1.43\%).

94) Prausnitz and Susskind 1962 (pulsed $9270 \mathrm{MHz}$, stab. $9040 \mathrm{MHz}$; 2.54\%)

95) Sperandio 2013 (780 nm, stab. 799.0;2.4\%)

96) Frigo 2009 (660 nm; stab. 674.0; 2.1\%)

97) Gomes Henriques, 2014 (660 nm; stab. 674.0; 2.1\%)

98) Sperandio $2013(660 \mathrm{~nm}$, stab. 674.0;2.1\%)

99) Setlow 1993 (436 nm, 449.8, 3.07\%)

100) Setlow 1993 (405 nm, 399.5, 1.38\%)

101) Popp 1976 (380 nm, 373.8; 1.66\%)

102) Setlow 1993 (365 nm, 373.8, 2.35\%)

103) Belloni 2005 (308 nm, 315.65; 2.42\%)

104) De Gruijl 1993 (293 nm, 299.55, 2.19\%)

*All further details on the total bibliography of the analyzed biomedical literature, with the related registered frequencies and experimental conditions, belonging to the Figure 2 and Figure 3, can be found on line, in reference 122 of ResearchGate. 